\title{
POLÍTICA FISCAL Y GASTO EN PENSIONES MÍNIMAS Y ASISTENCIALES
}

\author{
Salvador Valdés Prieto ${ }^{1}$
}

\begin{abstract}
El Poder Ejecutivo informó a la Comisión de Reforma Previsional que "La envergadura de los compromisos fiscales futuros generados por el sistema de pensiones confirma la necesidad de un rediseño (para) contar con (un) financiamiento sostenible”. Este trabajo encuentra que ese diagnóstico es errado. El error se origina en una omisión de la Dirección de Presupuestos, que no proyectó el gasto fiscal en pensiones mínimas del sistema antiguo, un componente que según nuestra estimación alcanza a partir de mayo de 2006 a \$ 219.162 millones de pesos al año. Al tomar en cuenta la presencia de este gasto, y su gradual caída durante las próximas dos décadas, se encuentra que el gasto total en subsidios de pensión mínima, incluyendo al del sistema nuevo, subiría en sólo 0 a 0,09\% del PIB en los próximos 20 años. Este incremento no tiene envergadura para afectar la sostenibilidad del financiamiento.
\end{abstract}

Salvador VAldÉs. Doctor en Economía , MIT; Ingeniero Civil, P. Universidad Católica de Chile. Profesor del Instituto de Economía de la P. Universidad Católica de Chile e Investigador del Centro de Estudios Públicos.

${ }^{1}$ Agradezco los comentarios de un árbitro anónimo, especialmente respecto de la sección 4. Sin involucrar a nadie, agradezco también los comentarios de Harald Beyer, Juan Luis Correa, Rosanna Costa, Hernán Cheyre, Juan Andrés Fontaine, Rolf Lüders, Andrés Passicot, Carlos Vidal-Meliá, Rodrigo Vergara, Joaquín Vial y los demás asistentes al seminario realizado en el CEP el 15 de junio de 2006. Agradezco la eficiente ayuda de Gonzalo Valdés E. y Cristián van Rysselberghe.

Estudios Públicos, 103 (invierno 2006). 
El trabajo también evalúa el impacto fiscal del aumento de gasto en pensiones legislado en abril de 2006. Se encuentra que tuvo el mismo costo fiscal que la acumulación de 20 años del proceso de envejecimiento y de crecimiento de los salarios reales.

También se critican aspectos del proyecto de Ley de Responsabilidad Fiscal presentado por el gobierno, basados en ciertos conceptos contables que promovió la Dirección de Presupuestos antes del auge del cobre. Se propone avanzar hacia una contabilidad fiscal devengada, reconocer provisiones dentro del patrimonio fiscal y formar reservas para respaldar pasivos y provisiones.

\section{Introducción}

$\mathrm{D}$ esde el año 2000 — cuando el precio del cobre era bajo — y hasta hoy, los informes de la Dirección de Presupuestos al Congreso sostuvieron que el gasto fiscal futuro en pensiones asistenciales y mínimas sería muy alto, y además atribuyeron esto a debilidades de la reforma de 1980 al sistema de pensiones. Ahora que estos diagnósticos han sido reiterados por el Poder Ejecutivo ante el Consejo Asesor Presidencial sobre Reforma Previsional, y en el proyecto de Ley sobre Responsabilidad Fiscal, este artículo busca evaluar su validez.

El gasto fiscal en subsidios de pensión mínima es la suma del gasto fiscal en subsidios de pensión mínima que hace el sistema antiguo, más los gastos análogos en favor de los afiliados del sistema de capitalización individual (nuevo). Sin embargo, las proyecciones que la Dirección de Presupuestos publicó en 2000-2006 no consideraron el gasto fiscal en subsidios de pensión mínima en el sistema antiguo. Esa omisión —reiterada a pesar de diversas advertencias - sesga las proyecciones del gobierno sobre la tendencia del gasto total en estos subsidios.

Este trabajo estima por primera vez el gasto fiscal en pensión mínima del sistema antiguo, con una técnica nueva que requiere pocos datos y se explica en el Anexo 1. Se encuentra que ese gasto habría alcanzado a partir de mayo de 2006 a \$ 219.162 millones de pesos al año, es decir 0,38\% del PIB, aunque la estimación es conservadora.

Esta cifra integra la base de comparación que se usa para determinar la tendencia que tendrá el gasto fiscal total en pensiones mínimas en las próximas dos décadas. Combinando esta cifra con las proyecciones del 
Fondo Monetario Internacional (2005), se encuentra que si las pensiones mínimas subieran a la par de los salarios reales, el Estado chileno enfrentaría una tendencia levemente creciente en el gasto fiscal en subsidios de pensiones mínimas en los próximos 20 años. La magnitud absoluta del incremento de su proporción respecto al PIB estará entre 0 y 0,09\% del PIB. Sumando la tendencia de aumento en el gasto en pensiones asistenciales, se proyecta un incremento absoluto de 0,18 a 0,27\% del PIB. Esta cifra es tan modesta que sería fácilmente financiable aunque no existiera el "dividendo por término de la transición iniciada con la reforma de 1980”, originado en el paso del sistema de "reparto" al de capitalización individual.

Por ende, este trabajo descarta el diagnóstico que el Poder Ejecutivo ofreció a la Comisión de Reforma Previsional, en cuanto a que "La envergadura de los compromisos fiscales futuros generados por el sistema de pensiones confirma la necesidad de un rediseño (para) contar con (un) financiamiento sostenible”. Un rediseño se justifica por otras razones, pero no porque esté en duda la sostenibilidad del financiamiento fiscal. Contrariamente a lo afirmado por el Poder Ejecutivo (2006), la reforma de 1980 protegió a Chile del riesgo fiscal causado por el proceso de envejecimiento.

El diagnóstico ofrecido al Consejo Asesor Presidencial para la Reforma Previsional por el Poder Ejecutivo (2006) también sostiene que “el déficit total del sistema de pensiones entre 2005 y 2010 alcanzará a 4,8\% del PIB, superando ampliamente las expectativas iniciales respecto de los efectos del proceso de reforma provisional (de 1980)”. Arenas y Mesa-Lago (2006) reiteran afirmaciones similares en la Oxford Review of Economic Policy.

Encontramos que la atribución de un déficit de 4,8\% del PIB a la reforma de 1980 es errónea. Esa cifra incluye las pensiones a carabineros, gendarmes y militares, cuyo déficit no puede atribuirse a la reforma de 1980 porque sus planes no fueron reformados en esa ocasión. También incluye el gasto en pensiones asistenciales y subsidios de pensión mínima, que tampoco fueron reformados en 1980. Una vez limpiado de estos efectos, el déficit residual es de sólo 2,6\% del PIB para 2005-2010.

Una buena parte de este déficit residual tampoco puede ser atribuido a la reforma de 1980. El indicador adecuado para medir el impacto fiscal del tránsito desde el sistema de reparto al de capitalización es el flujo de cotizaciones desviadas hacia los nuevos fondos de pensiones, que fue sólo 1,7\% del PIB en 1982 y estimamos en 1,2\% del PIB para 2005. La diferencia se explica por los aumentos de pensiones generales del INP (entidad que administra el sistema antiguo) aplicados desde 1987, y por las pensiones a exonerados políticos que fueron creadas en los años 90. El impacto de estas medidas sobre el presupuesto del INP no puede ser atribuido a la reforma de 
1980. También influye la rebaja en la tasa de cotización aplicada en 1981, que fue compensada con una mayor tasa de IVA, como recomienda la ciencia económica. Este paquete tiene un efecto nulo a nivel de todo el fisco, siendo irrelevante el efecto sobre el presupuesto del INP. Proyectamos que el costo fiscal del tránsito de reparto a capitalización será cercano a 1,05\% del PIB en 2008, es decir, 78\% menor que lo indicado por el Poder Ejecutivo (2006).

El sistema político puede ser generoso y elevar los subsidios de pensión mínima (que cubren al sistema nuevo y antiguo). Pero ¿en cuánto aumentaría el gasto fiscal? Nuestro modelo es el primero en responder, y encuentra que un alza de $10 \%$ en la pensión mínima eleva el subsidio en el sistema antiguo en 25\%. Encontramos que el aumento legislado en abril de 2006 elevó al gasto fiscal a 20 años plazo en la misma cantidad que el efecto acumulado que tendrían el envejecimiento y el crecimiento de salarios reales durante 20 años.

La siguiente cuestión es si el Congreso fue alertado adecuadamente respecto del costo fiscal que significará este aumento de las pensiones mínimas y asistenciales, al interactuar con el proceso de envejecimiento. En general, se requiere que el fisco lleve contabilidad devengada para que el Congreso pueda evaluar correctamente el costo de su generosidad. Esa contabilidad obliga a reconocer pasivos exigibles y permite provisiones. Ambos deben ser cubiertos acumulando fondos de reserva. Los fondos destinados a ellos se restan del gasto fiscal potencial, mostrando al Congreso el verdadero dilema que debe resolver al aprobar una medida que eleva el gasto. La contabilidad devengada también permite evaluar la alternativa de ajustar parámetros como edades de pensión y cantidad de enfermedades cubiertas por el plan AUGE.

Este estudio evalúa también algunos conceptos contables promovidos por la Dirección de Presupuestos antes del auge del cobre, encontrando que no distingue adecuadamente entre pasivos contables y riesgos fiscales. Ambos pueden justificar que se acumulen reservas, pero los montos de los “riesgos fiscales” sólo deberían ser reconocidos como provisiones al interior del patrimonio fiscal, porque no son pasivos exigibles.

La conclusión critica algunos elementos del proyecto de Ley de Responsabilidad Fiscal. Se propone que la ley obligue a determinar los pasivos exigibles creados por el plan AUGE y otros programas, en adición a los pasivos por garantías contractuales a los concesionarios de obras públicas que ya han sido cuantificados. Además, se propone que los "riesgos fiscales”, por ejemplo los asociados al gasto general en salud y el gasto en pensiones asistenciales y mínimas, sean cuantificados y reportados en un 
nuevo "Informe de Riesgos Fiscales". También se propone rechazar la denominación "para Pensiones" del fondo de reserva del proyecto de ley, porque la destinación específica es ineficiente y porque es probable que los mayores pasivos y provisiones se originen en el plan AUGE y en los subsidios a la salud.

\section{El gasto fiscal en subsidio de pensión mínima}

En su informe de septiembre de 2000, para efectos del presupuesto de 2001, y reiterado nuevamente en los informes de 2002 y 2003, mucho antes del auge del cobre, la Dirección de Presupuestos sostuvo que "Este pasivo [se refiere a los gastos en pensiones mínimas del sistema de capitalización individual] tiene su origen en la implementación de la Reforma Previsional de 1981..." (Aspectos Macroeconómicos, 2001, p. 48).

Continuó insistiendo en esta posición en sus informes de 2004 y 2005 afirmando que "La garantía estatal de pensión mínima nace con la reforma previsional de 1981..." (Informe de Finanzas Públicas para 2006, septiembre 2005, p. 169).

Esta sección demuestra que también existe gasto fiscal por subsidio de pensión mínima en el sistema antiguo, y que el subsidio de pensión mínima es muy anterior a la creación del sistema nuevo en 1980.

Este error tiene serias consecuencias para la estimación del gasto fiscal. Lo que interesa para determinar la tendencia de gasto fiscal en subsidios de pensión mínima es la suma de ambos gastos en subsidio de pensión mínima, no la tendencia de una parte de ellos (Bennett y SchmidtHebbel, 2001). Sin embargo, si el gobierno cree que sólo existe el componente iniciado en 1981, usará una base de proyección sesgada, y llegará a conclusiones erradas respecto a la tendencia del gasto fiscal en los próximos 20 años.

\subsection{Existencia del subsidio de pensión mínima en el sistema antiguo}

La garantía de pensión mínima en el sistema antiguo existe desde 1952 en el caso del Seguro Social (Ley 10.383). En efecto, el art. $7^{\circ}$ transitorio de la Ley 10.383 reza:

Las personas que gozan de pensión de vejez o invalidez de la Caja del Seguro Obligatorio, inferiores a \$1.000 mensuales, tendrán derecho a que ellas sean elevadas a esa suma, desde la vigencia de esta ley (...). Igual derecho tendrán los ex im- 
ponentes mayores de 65 años (...) que hubieren rescatado su pensión de vejez (...) que tuvieren a lo menos 300 semanas de imposiciones (...). (Diario Oficial, 8 de agosto 1952).

El Informe Prat (1959, Vol. IV, p. 139), lo confirma:

La última ley de mínimos fijó como monto mínimo de la pensión la suma uniforme de \$22.000 (art. 37 de Ley 13.305) [para el caso de invalidez, se reporta en p. 140 que el mismo mínimo se aplicaba a las pensiones de vejez].

Desde 1963 la pensión mínima fue extendida a casi todas las demás cajas (Ley 15.386), unificando este importante componente del pilar solidario del sistema chileno de pensiones. El conocido texto Derecho de la Seguridad Social (1977), de Patricio Novoa F., confirma que la pensión mínima fue creada en 1952 y generalizada en 1963. José Pablo Arellano (1985) reporta el monto de la pensión mínima en cada año desde 1952 hasta 1979. Wagner (1991, Cuadro $N^{0}$ 7) ofrece cifras comparativas con el salario mínimo. Zurita (1994) reporta la legislación de pensión mínima en el sistema antiguo.

\section{2. ¿Afectó la reforma de 1980 al subsidio de pensión mínima?}

CEPAL, en su estudio Protección Social de Cara al Futuro, de febrero de 2006, ofrece el siguiente relato sobre el origen del subsidio de pensión mínima. Después de sostener que las reformas como la de 1980 en Chile

eliminan los elementos de solidaridad (contenidos) en los modelos de reparto (p. 124) ${ }^{2}$,

afirma que en las reformas que pasan del reparto a la capitalización, como la de 1980 ,

para remediar [la eliminación de la solidaridad inherente a los sistemas de reparto] se incorporaron subsidios de pensión mínima (...) (pp. 131-132).

La historia en Chile fue otra: para remediar la falta de solidaridad de las fórmulas de beneficio según años de servicio del sistema antiguo, se

${ }^{2}$ CEPAL no afirma que los antiguos sistemas de reparto de América Latina fueran solidarios en términos efectivos. Numerosos estudios muestran que eran regresivos; también en Chile. Ver citas en Valdés (2002), pp. 82-83. 
introdujo el subsidio de pensión mínima en 1952, y como eso resultó insuficiente, se creó la pensión asistencial en 1975. Mucho después, la reforma de 1980 se abocó a mejorar las pensiones contributivas para la clase media, es decir aquellas pensiones mayores que la pensión mínima y que intentan ayudar a sus afiliados a evitar caídas predecibles de nivel de vida al jubilar. Su objetivo es aliviar la imprevisión, y no redistribuir ingreso, en el entendido de que para eso basta con el sistema tributario y el sistema de gasto público.

La reforma de 1980 se limitó a compatibilizar el nuevo sistema de capitalización individual con los subsidios de pensión mínima y asistencial, ambos preexistentes. Esto se demuestra por el hecho de que la reforma de 1980 fijó el monto de la pensión mínima para el sistema de capitalización individual en aquella cifra que el sistema antiguo utilizara como pensión

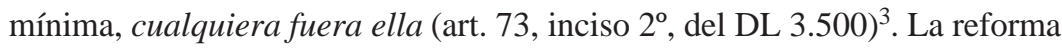
de pensiones de 1980 preservó la unificación del subsidio de pensión mínima lograda en 1963.

\subsection{Cómo funciona el subsidio de pensión mínima}

La pensión mínima del sistema antiguo se gatilla cuando la pensión determinada por la fórmula de beneficio del régimen previsional aplicable (basada en años de cotización y en salarios cotizados, y por ende autofinanciada desde el punto de vista del afiliado) resulta inferior al monto de la pensión mínima. En el Gráfico $\mathrm{N}^{\circ} 1$, la pensión autofinanciada por fórmula es la línea de puntos, y el subsidio de pensión mínima en el sistema antiguo es la barra que continúa sobre los puntos. El beneficiario recibe la suma de ambas barras, es decir el monto de la pensión mínima. Usando fórmulas, el monto de este subsidio es:

\section{(1) $S P M=$ Max $\{M P M-$ Pensión Fórmula; 0$\}$}

donde MPM = monto de la pensión mínima.

${ }^{3}$ El requisito de 20 años de cotización también fue copiado, ya que es similar a uno de los que exige el Seguro Social desde 1952 y que continúa vigente hasta hoy. Los requisitos de la pensión mínima en el sistema antiguo son menos exigentes que en el sistema nuevo, como se explica más adelante. A cambio, el sistema nuevo contiene un beneficio nuevo, que es la devolución de todas las cotizaciones más intereses a quienes no cumplan el requisito para tener subsidio de pensión mínima. 
GRÁFICO No ${ }^{\circ}$ : $\quad$ SUBSIDIO DE PENSIÓN MÍNIMA EN EL SISTEMA ANTIGUO

(Para un individuo de sexo y rango de edad prefijados)

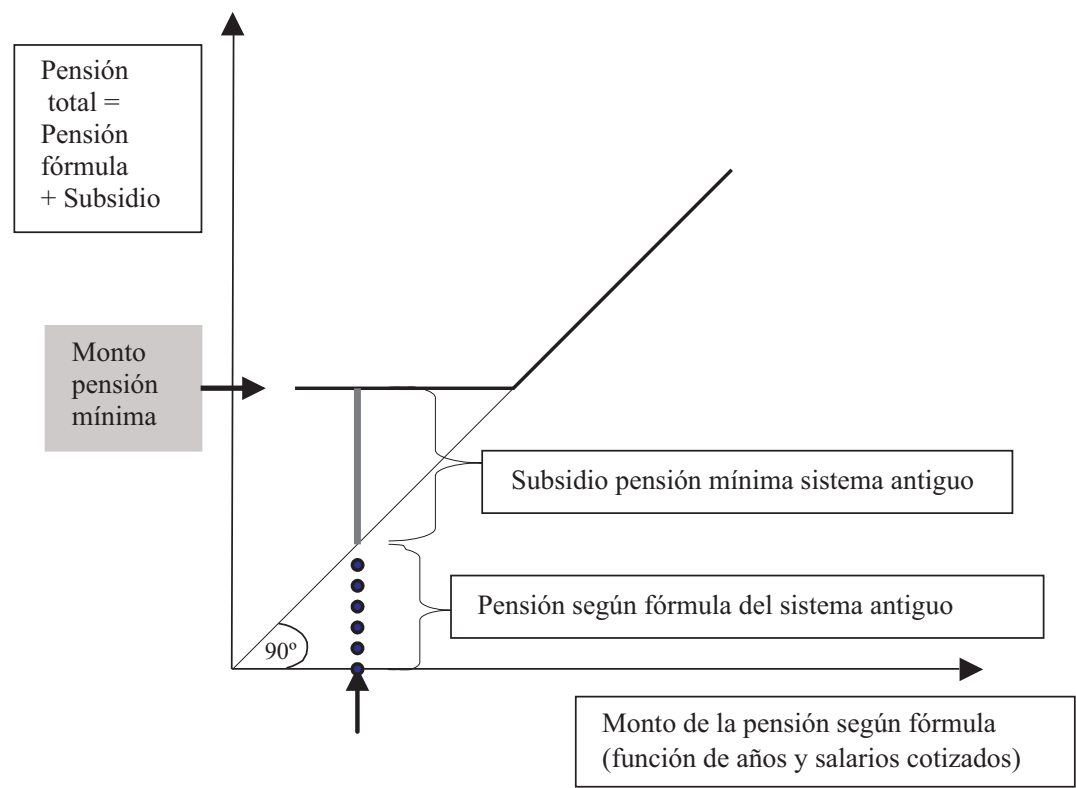

En el sistema de capitalización individual el subsidio de pensión mínima opera con el mismo esquema, con la diferencia de que la "pensión fórmula” es reemplazada por la pensión autofinanciada con las cotizaciones y rentabilidades, sea ella de retiro programado o de renta vitalicia. El monto de la pensión mínima está unificado entre los sistemas nuevo y antiguo.

En el sistema antiguo, la pensión fórmula es el producto de la "tasa de reemplazo" por el "salario base". El salario base es el promedio de los últimos tres o cinco años de empleo o calendario, según la caja. La "tasa de reemplazo" es un coeficiente que se determina con una fórmula establecida en la ley, en función de las semanas o años de cotización. El Gráfico $\mathrm{N}^{\circ} 2$ muestra las fórmulas que usaba el sistema antiguo en sus tres mayores cajas (SSS, Empart y Canaempu), ajustando por el factor de corrección del art. $4^{\circ}$ del DL 3.501. Allí se ve que la máxima tasa de reemplazo del SSS es $58,2 \%$ (y no $70 \%$ como se cree comúnmente).

${ }^{4} \mathrm{El}$ SSS usa la siguiente fórmula para los hombres, una vez que completan 800 semanas de cotización: Pensión Fórmula $=\left[0,50+0,01 \mathrm{x}\right.$ Parte Entera $\left(\mathrm{N}^{\circ}\right.$ Semanas de Servicio/50) - 10] x $(1 / 1,2020) \times$ (Promedio de salario en 60 meses calendario anteriores al inicio de la pensión), con un máximo de 1.500 para las semanas computables. El 
GRÁFICO Nº 2: TASA DE REEMPLAZO DE LA PENSIÓN FÓRMULA EN EL SISTEMA ANTIGUO

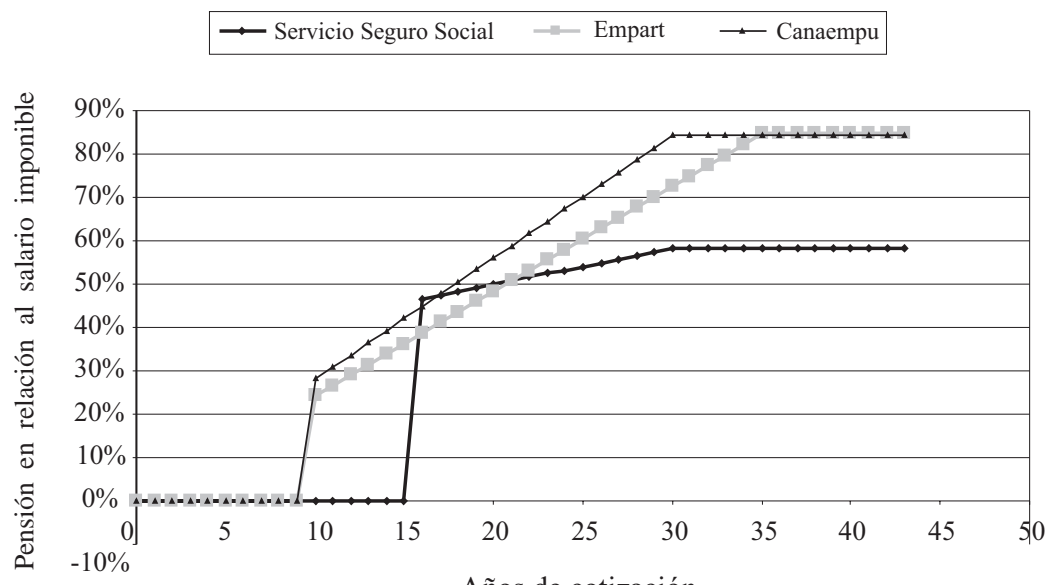

Años de cotización

\subsection{Impacto de este error sobre las proyecciones fiscales}

El Gráfico № 3 muestra que, a medida que los afiliados del sistema antiguo fallecen a lo largo de las décadas, el sistema antiguo es sustituido por el sistema de capitalización individual.

Se observa que la tendencia del gasto es fuertemente alterada si se omite el gasto en subsidios de pensión mínima del sistema antiguo, pues la base de comparación queda minimizada. Omitir el gasto en el sistema antiguo equivale, en el Gráfico $\mathrm{N}^{0} 3$, a proyectar la línea de puntos solamente. También Bennett y Schmidt-Hebbel (2001) afirmaron que lo que interesa para la política fiscal es la tendencia de la suma de ambos gastos en pensiones mínimas.

A pesar de las objeciones recibidas en seminarios, el subdirector de Presupuestos presentó en varias oportunidades proyecciones para el gasto en pensión mínima del sistema de capitalización individual solamente, omi-

divisor 1,2020 fue introducido por el D.L. 3.501 de 1980, art $4^{\circ}$, inciso $6^{\circ}$. Hay divisores similares en las demás cajas. Estos divisores fueron necesarios para evitar un aumento no planeado en las nuevas pensiones concedidas a partir de 1981, que se habría generado porque el término de las cotizaciones de cargo del empleador y el inicio de su pago total por parte del trabajador conllevó un aumento por ley de los salarios contractuales para compensar. 


\section{GRÁFICO N 3: $\quad$ GASTO FISCAL TOTAL EN PENSIÓN MÍNIMA COMO \% DEL PIB}

Gasto fiscal en sub. PM como \% PIB

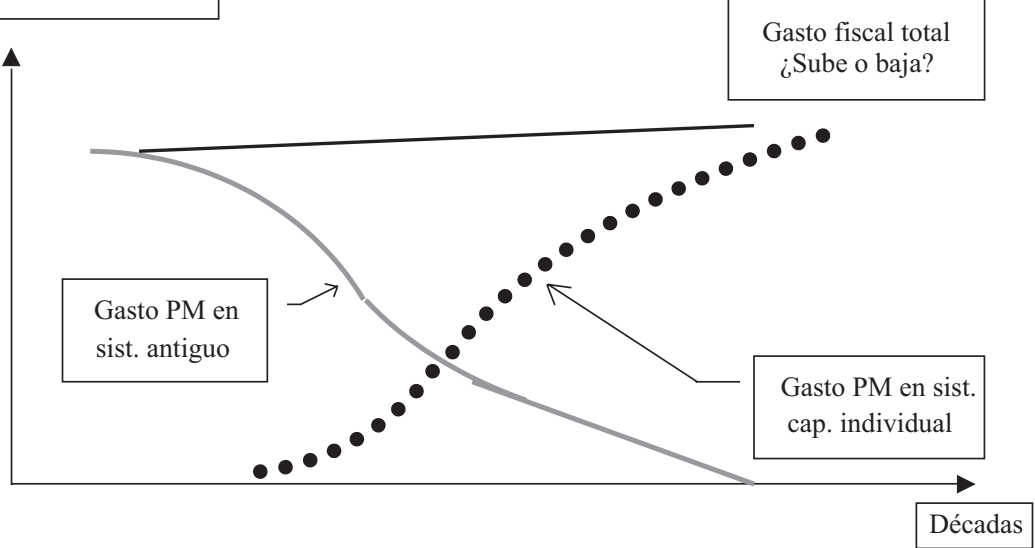

GRÁFICO N ${ }^{\circ}$ 4: $\quad$ PROYECCIÓN DEL GASTO EN GARANTÍA ESTATAL EN PENSIÓN MÍNIMA: 2004-2020 (MM\$ DE 2004)

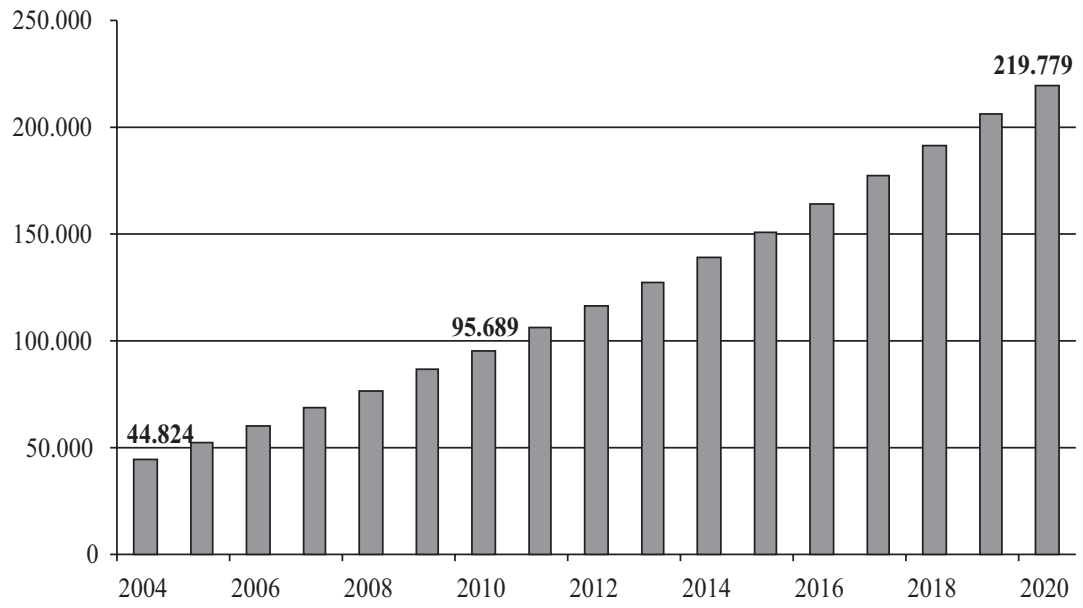

Fuente: Arenas (2004). 
tiendo al sistema antiguo. Por ejemplo, en CEPAL en enero de 2004, antes del auge del cobre, presentó el Gráfico $\mathrm{N}^{\circ} 4$, dando la impresión de que el gasto crecería rápido.

Durante el período 2000-2005 la Dirección de Presupuestos nunca presentó al Congreso, y suponemos que nunca la realizó, una proyección de gastos futuros en subsidio de pensión mínima en las cajas del sistema antiguo, que es un requisito indispensable para medir la tendencia del gasto fiscal total en pensiones mínimas.

Si bien la ausencia de información digitalizada en el INP sobre las historias previsionales de sus pensionados es un obstáculo para cualquiera que desee hacer una estimación, como lo fue para este trabajo, es posible que el obstáculo mayor haya sido la creencia a priori de que el subsidio de pensión mínima fue creado en 1981 y que cubría sólo al sistema nuevo.

En efecto, el director y el subdirector de Presupuestos escribieron ya en 1999 que "la pensión mínima garantizada por el Estado será un legado fiscal de alto costo de la privatización del sistema de pensiones”, es decir un legado de la reforma de 1980, siendo que la pensión mínima fue creada en 1952 (Arenas y Marcel, 1999, p. 166).

\subsection{Otras interpretaciones}

Uno de los objetivos declarados de la reforma previsional de 1980 fue reducir los compromisos fiscales. Sin embargo, la reforma de 1980 nunca tuvo entre sus objetivos reducir los compromisos fiscales por pensión mínima (y tampoco por pensión asistencial), como ya se ha demostrado. Como los subsidios de pensión mínima no son beneficios asociados al sistema nuevo, sino parte de un sistema independiente, la promesa de reducir los compromisos fiscales sólo puede entenderse en el sentido de reducir el gasto fiscal en pensiones fórmula.

Conviene aclarar, en todo caso, que la reforma de 1980 tampoco redujo los compromisos fiscales existentes por concepto de pensiones fórmula. Ellos fueron reducidos antes, por otras reformas realizadas en 1979. Con todo, al cambiar el financiamiento desde reparto a capitalización individual, la reforma de 1980 protegió al fisco del envejecimiento, y en este sentido más amplio redujo un riesgo fiscal emergente.

Otra posible explicación para las afirmaciones citadas es que, como el gasto en subsidio de pensión mínima en el sistema antiguo está incluido en un ítem de gasto más amplio, llamado "déficit operacional del sistema antiguo” y del cual existen proyecciones de largo plazo, ya estaría conside- 
rado en esta segunda proyección. Nos parece que esa eventual explicación está equivocada, porque:

a) No se puede determinar la tendencia del gasto fiscal total en pensiones mínimas sin medir correctamente el punto de partida (el gasto en la actualidad). Al omitir un componente de la base de comparación, se exagera la tendencia de crecimiento.

b) Para estimar el verdadero "dividendo por término de la transición de reparto a capitalización”, es indispensable depurar al “déficit operacional” de su gasto fiscal en subsidio de pensión mínima. Al depurar, el dividendo por término de la transición se mostrará menor. El uso de cifras no depuradas puede promover un gasto exagerado.

c) Al tratar el costo de los subsidios de pensión mínima del sistema antiguo como si fueran gastos transitorios, se exagera el "costo de la transición” de la reforma de 1980.

\section{Estimación y proyección del gasto fiscal total en subsidios de pensión mínima}

El Gráfico No 3 abre la pregunta de si caerá o bajará el gasto fiscal total en pensiones mínimas en el largo plazo. Este trabajo busca proveer una respuesta empírica. Al respecto, hay factores que empujan el gasto fiscal total al alza y hay otros factores que lo empujan a la baja. El resultado neto es un tema empírico.

Un factor que empuja el total al alza es el envejecimiento demográfico, que elevará la fracción de personas sobre las edades de pensión mínima (60 las mujeres y 65 los hombres) dentro de la población total. Sin embargo, al nivel de todo el fisco, el envejecimiento también libera fondos destinados a los niños, como los gastos en educación y salud infantil.

Un segundo factor que empuja al alza el gasto fiscal total en pensiones mínimas es el crecimiento de los salarios reales. Una somera comparación internacional muestra que los países más ricos tienen pensiones mínimas más altas que los países pobres. Esta diferencia es aproximadamente proporcional a la diferencia entre salarios medianos.

Otro factor que hace variar el gasto fiscal en pensiones mínimas es el cambio en la generosidad de la ciudadanía, manifestada en aumentos o disminuciones del monto de la pensión mínima en relación al salario mediano. Un ejemplo es elevar en $10 \%$ el monto de las pensiones mínimas y asistenciales, como prometió la Presidenta Bachelet en su campaña presi- 
dencial, y cumplió en abril de 2006. En ese caso el efecto final puede ser un aumento de gasto, aunque la tendencia haya sido a la baja (ver Gráfico $\mathrm{N}^{\circ}$ 5).

Sin embargo, la generosidad puede devenir en populismo, definido como aquella competencia entre políticos que consiste en ofrecer subsidios al electorado, sin que éste aprecie que ellos mismos los pagarán a través de mayores impuestos o menos crecimiento. Este problema se alivia cuando la contabilidad fiscal se hace sobre una base devengada, reportando el incremento en pasivos o reservas del patrimonio fiscal que conlleva una determinada medida. En efecto, esa información obliga a constituir reservas de inmediato, mostrando con claridad que el costo económico de la medida puede ser mucho mayor que el costo de caja.

Por la vereda opuesta, hay factores que reducen gasto fiscal en pensiones mínimas: uno de ellos es un aumento en la tasa interna de retorno del sistema de pensiones contributivas para la clase media. Empíricamente, cuando se adopta el financiamiento por capitalización en reemplazo del financiamiento por reparto puro maduro, se logra un aumento de la rentabilidad para los aportes privados (no de la rentabilidad social). Con frecuencia este aumento supera dos puntos porcentuales anuales y en América Latina ha superado 4 puntos porcentuales (ver datos empíricos que avalan esto en Valdés (2002), Cuadros Nos. 9.1 y 9.2, para países industriales y para América Latina). Si además esa mayor rentabilidad se traduce en parte en mayores pensiones y no sólo en menores tasas de cotización, entonces las pensio-

\section{GRÁFICO N 5: $\quad$ EFECTO DEL AUMENTO DE PENSIONES DE 10\% APROBADO EN 2006}

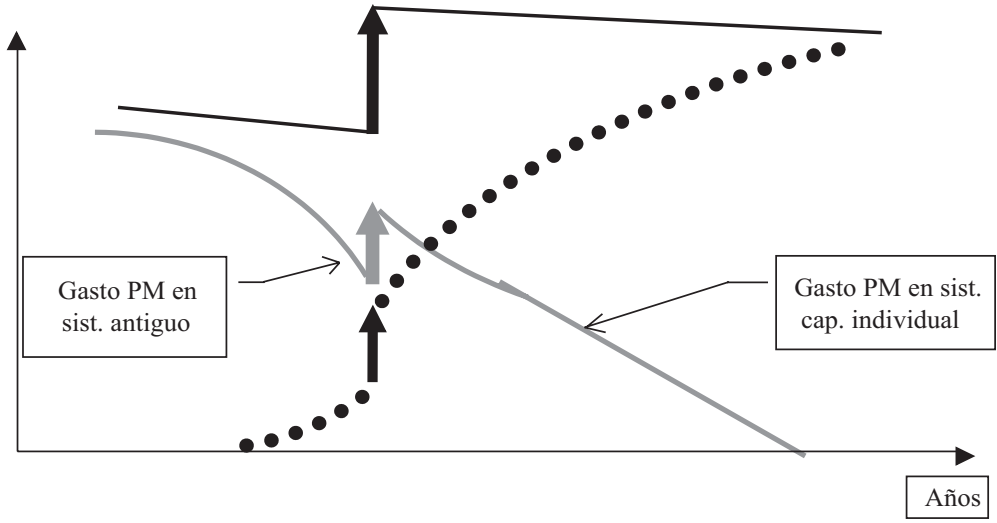


nes autofinanciadas suben con la adopción de la capitalización, reduciendo el gasto fiscal en pensiones mínimas en el largo plazo.

Un segundo factor se da cuando la rentabilidad efectiva en la capitalización individual resulta ser mayor que la esperada cuando se eligió la tasa de cotización obligatoria. Por ejemplo, si la rentabilidad real se mantiene por dos décadas en 6,5\% real, pero la tasa de cotización se eligió para una rentabilidad de $4,5 \%$ real anual, entonces, ese $2 \%$ anual adicional eleva las pensiones autofinanciadas en $25 \%$ para una misma historia de cotizaciones ${ }^{5}$. Eso también reduce el gasto fiscal en pensiones mínimas.

3.1. Estimación del subsidio de pensión mínima en el sistema antiguo, en 2004

Para saber si el gasto fiscal total en pensiones mínimas subirá o bajará en las próximas décadas, es esencial contar con una base de comparación válida. Ello exige determinar cuánto es hoy el gasto fiscal en subsidios de pensión mínima en el sistema antiguo. Elegimos hacerlo para diciembre de 2004, una fecha anterior al alza de 10\% aprobada por el Congreso en abril de 2006, con el fin de aprovechar los datos de otros estudios previos.

El método consiste en estimar el número de pensiones menores o iguales a la mínima, y luego multiplicar por el monto estimado del subsidio promedio por beneficiario. Esto se hace por separado para cada categoría de beneficiarios.

En la primera etapa, referida al número de personas que reciben algún subsidio de pensión mínima, es necesario tomar en cuenta que su monto no es único. Primero, para las viudas y madres de filiación no matrimonial la pensión mínima representativa es el 60\% de la pensión mínima que habría tenido el causante en caso de estar vivo (en el Anexo 1 se justifica esta cifra como un promedio de los diversos casos reales). Segundo, el monto de la pensión mínima de los causantes (por vejez e invalidez) depende de su edad, según tres tramos en orden creciente: menores de 70 años, entre 70 y 75, y mayores de 75 años ${ }^{6}$.

Riesco (2005) reporta la distribución del número de pensionados según categorías en diciembre de 2004. El Cuadro $N^{0} 1$ combina sus datos con

${ }^{5}$ Ver Cuadro No VIII.4 en p. 182 de Superintendencia de AFP (2002), "El Sistema Chileno de Pensiones”, quinta edición, en www.safp.cl

${ }^{6}$ Los incrementos por edad son en la actualidad 9,3\% y 6,7\% sin contar los componentes fijos como Bono de Invierno y Aguinaldos de Fiestas Patrias y Navidad. 
información directa del INP respecto del número de receptores de pensión mínima (tercera columna).

El Cuadro $\mathrm{N}^{\mathrm{o}} 1$ revela que el porcentaje de pensionados del sistema antiguo que recibió subsidio de pensión mínima fue 61,6\% en diciembre de 2004. Esta cifra es alta.

El subsidio medio por beneficiario se estima en el Anexo 1, con un procedimiento novedoso que podría tener aplicación más general. Es sabido que los salarios tienen una densidad asimétrica, con una media notoriamente superior a la mediana, que a su vez es superior a la moda. El método habitual de suponer una densidad uniforme entre los puntos conocidos de la distribución acumulada no es satisfactorio, porque introduce artificialmente fuertes saltos en la densidad. Esos saltos pueden resultar determinantes para algunos resultados, debido a la no linealidad del gasto fiscal respecto al monto de la pensión mínima. Tampoco consideramos aceptable construir una densidad empírica con datos de la CASEN 2003, debido a que los ingresos autorreportados tienen un sesgo desconocido respecto a los

CUADRO N ${ }^{\circ}$ 1: $\quad$ NÚMERO DE BENEFICIARIOS SUBSIDIO DE PENSIÓN MÍNIMA, SISTEMA ANTIGUO, DICIEMBRE 2004

\begin{tabular}{|c|c|c|c|c|}
\hline & $\begin{array}{l}\text { Número de } \\
\text { beneficiarios }\end{array}$ & $\begin{array}{c}\text { Pensión } \\
\text { media (\$/mes) }\end{array}$ & $\begin{array}{c}\text { Número } \\
\text { bajo la } \\
\text { pensión mínima }\end{array}$ & $\begin{array}{c}\% \\
\text { Recibiendo } \\
\text { subsidio } \\
\text { pensión mínima }\end{array}$ \\
\hline Vejez & 317.276 & $\$ 113.784$ & 253.903 & $80,0 \%$ \\
\hline Antigüedad & 93.761 & $\$ 229.274$ & 7.777 & $8,3 \%$ \\
\hline Invalidez & 138.975 & \$ 132.722 & 93.587 & $67,3 \%$ \\
\hline Viudez & 239.885 & $\$ \quad 84.849$ & 133.094 & $55,5 \%$ \\
\hline $\begin{array}{l}\text { Madre filiación no } \\
\text { matrimonial (montepíos) }\end{array}$ & 12.294 & $\$ \quad 46.283$ & 6.129 & $49,9 \%$ \\
\hline TOTAL & 802.191 & & 494.490 & $61,6 \%$ \\
\hline $\begin{array}{l}\text { Memo: exonerados, } \\
\text { reparaciones y otras }\end{array}$ & 38.330 & $\$ 231.124$ & 2.658 & $6,9 \%$ \\
\hline Memo: orfandad & 43.960 & $\$ \quad 50.205$ & 10.966 & $24,9 \%$ \\
\hline
\end{tabular}

Fuentes: primeras dos columnas de Riesco, M. (2005, p. 22). Considera a todas las cajas civiles. No todos son mayores que $60 \mathrm{M} / 65 \mathrm{H}$, debido a que algunos inválidos, antigüedades, viudas y madres son menores. El número total de pensionados mayores de $60 \mathrm{M} / 65 \mathrm{H}$ es 743.102 (Riesco, p. 18). Si bien el total de pensionados con subsidio y mayores de $60 \mathrm{M} / 65 \mathrm{H}$ es menor que 379.627 , el gasto fiscal en subsidio de pensión mínima incluye los subsidios a inválidos y viudas menores que esas edades.

La columna tres se obtuvo directamente en el INP, Departamento de Estadística. 
ingresos imponibles válidos para determinar los subsidios. Para ilustrar, se sabe que la subdeclaración promedio respecto a los ingresos de cuentas nacionales es $20 \%$, pero no se ha revelado cómo se distribuye por deciles y por otras agrupaciones. Es prioritario evitar sesgos de esta magnitud.

Nuestro método es ajustar una función de densidad de probabilidad continua a la distribución de salarios imponibles observada en registros administrativos. Como se publican pocos puntos de esa distribución acumulativa, el intervalo de confianza en el $90 \%$ de nuestros resultados es amplio. Lo ideal sería que la Superintendencia de AFP reportara la distribución acumulada de salarios cada \$5.000, y no cada \$ 50.000 como hace hasta ahora. Una vez determinados los parámetros de esa densidad de probabilidad, ella permite calcular con métodos numéricos el subsidio medio para aquella parte de la distribución de pensiones fórmula que queda por debajo de la pensión mínima pertinente.

Siguiendo una larga literatura empírica en economía iniciada por Roy (1950), la densidad de probabilidad utilizada es la lognormal. También existe sólida evidencia favorable para su uso en Chile (Chumacero y Paredes, 2005). Sus parámetros se estimaron con la distribución de salarios imponibles reportados en 2004 al sistema de capitalización individual. Nos parece válido usar la distribución de 2004, en vez de las distribuciones para los años en que los actuales pensionados determinaron su salario base, porque otros estudios indican que la distribución del ingreso en Chile ha variado poco en los últimos 40 años (Beyer, 1997, 2000).

El resultado también queda determinado por la esperanza de vida (o edad promedio) de cada categoría de beneficiarios al momento de emitir cada pensión, por los salarios que entraron al promedio de cinco años que considera la fórmula, y por la tasa de reemplazo que ofrece la fórmula de beneficio del SSS, porque la gran mayoría de los beneficiarios de subsidio pertenece a esa caja. Su fórmula de beneficio contiene numerosas complicaciones indicadas en el Anexo 1.

El subsidio medio resulta alto porque la mayoría de los jubilados actuales se pensionó antes de la fuerte alza de los salarios reales verificada en 1988-2004. Esa alza fue acompañada de un aumento aún mayor en las pensiones mínimas. En cambio, las pensiones fórmula quedan fijas en términos reales una vez concedidas, según dispone la propia fórmula. El resultado de las simulaciones con MAPLE está en el Cuadro $\mathrm{N}^{\circ} 2$.

Sumando causantes y viudas, concluimos que, con un $90 \%$ de confianza, el gasto fiscal en subsidio de pensión mínima del sistema antiguo, durante el año 2004, estuvo entre \$ 152.946 millones y \$ 200.695 millones de pesos. En el escenario central el gasto fiscal en subsidios de pensión míni- 
CUADRO No 2: $\quad$ GASTO FISCAL EN SUBSIDIO DE PENSIÓN MÍNIMA SISTEMA ANTIGUO, AÑO 2004

\begin{tabular}{lcccc}
\hline Grupo & $\begin{array}{c}\text { Escenario } \\
\text { de gasto } \\
(90 \% \text { confianza })\end{array}$ & $\begin{array}{c}\text { Subsidio por } \\
\text { beneficiario } \\
(\$ / \text { mes })\end{array}$ & $\begin{array}{c}\mathbf{N}^{\circ} \text { de } \\
\text { beneficiarios }\end{array}$ & $\begin{array}{c}\text { Gasto fiscal } \\
\text { anual } \\
(\text { mill. } \$)\end{array}$ \\
\hline Causantes & Bajo & $\$ 21.072$ & & $\$ 89.834$ \\
& Medio & $\$ 26.340$ & 355.267 & $\$ 112.293$ \\
Alto & $\$ 31.607$ & & $\$ 134.747$ \\
Viudas & Bajo & $\$ 37.774$ & 139.233 & $\$ 63.112$ \\
& Medio & $\$ 38.396$ & & $\$ 64.152$ \\
& Alto & $\$ 39.471$ & & $\$ 65.948$ \\
\hline
\end{tabular}

ma equivale a $0,31 \%$ del PIB de $2004^{7}$. El intervalo de confianza va de $0,27 \%$ del PIB a $0,35 \%$ del PIB.

\subsection{Tendencia del gasto fiscal total en subsidio de pensión mínima}

La tendencia estimada aquí combina la base de comparación estimada en la sección anterior, con proyecciones realizadas por otros autores, en particular FMI (2005). Por tanto, las debilidades de esas proyecciones son heredadas por las proyecciones que siguen. Separamos la discusión de la tendencia en sus tres componentes principales: subsidio de pensión mínima en el sistema nuevo, en el sistema antiguo, y pensiones asistenciales.

\section{a) Subsidio de pensión mínima en el sistema de capitalización individual (SCI)}

En el año 2004 hubo 65.000 pensiones mínimas en el sistema nuevo (SCI). Su costo fiscal se estima en $0,08 \%$ del PIB $^{8}$.

Según Wagner (1991), en el largo plazo el gasto fiscal para el SCI estaría entre 0,12\% y 0,45\% del PIB. Zurita (1994) utilizó una metodología más avanzada que valora el riesgo de tasa de interés con teoría de opciones

${ }^{7}$ El PIB nominal de 2004 fue de $\$ 57.357$ millones de pesos.

${ }^{8} \mathrm{Sin}$ embargo, el subsidio devengado puede haber sido mucho mayor, porque aquellos pensionados con derecho a pensión mínima que están consumiendo el saldo de su cuenta individual están acumulando derechos a cobrar subsidios mayores al fisco una vez que su saldo se agote. No se conocen estimaciones de este efecto. 
y encontró que el costo fiscal de este subsidio estaría entre 3,01 y 3,77\% del PIB. Si bien esto parece mucho mayor, no lo es, porque la proyección de Zurita no es un flujo, sino el valor presente esperado del gasto para el conjunto de personas que "están actualmente afiliados”. Para anualizar la proyección de Zurita habría que multiplicarla por una tasa de interés (si es $5 \%$, habría que dividir por 20$)^{10}$.

La Dirección de Presupuestos, en su informe al Congreso de octubre de 2000 presentó una dramática proyección: el gasto en subsidio de pensión mínima del SCI subiría hasta 1,30\% del PIB en 2037, pudiendo variar entre 1,10\% y 1,60\% del PIB según cual fuera la rentabilidad promedio de los fondos de pensiones (Dipres, 2000, p. 48). Esto es, unas cinco veces la estimación de Wagner (1991).

Una razón de la discrepancia parece ser que no aquilataron la gran influencia en los resultados de Wagner y Zurita que tiene la modesta densidad de cotizaciones, al interactuar con el requisito de 20 años de cotizaciones. La "Encuesta de Historias Laborales y de Seguridad Social 2002” generó datos que confirmaron la modesta densidad ya advertida por Wagner y Zurita. El subdirector de Presupuestos admitió, en un encuentro de CEPAL en enero de 2004, que la proyección de gasto fiscal en subsidio de pensión mínima en el SCI para 2020 era ahora \$ 219.779 millones de pesos de 2004 (ver Gráfico No 4). Adoptando los supuestos de Bennett y SchmidtHebbel para la tasa de crecimiento del PIB real en 2004-2020, esta cifra equivale a sólo 0,17\% del PIB de $2020^{11}$.

${ }^{9}$ Ver también en Zurita (1994) p. 122, último párrafo, y p. 123, primer párrafo, donde compara con el valor presente de la estimación de Wagner (1991) y no con el flujo anual de Wagner.

${ }^{10}$ La proyección en Zurita (1994) contiene otros supuestos a mejorar: (a) utiliza la volatilidad diaria del valor cuota entre julio y octubre de 1993, para estimar la volatilidad del valor cuota a 40 años plazo. No se debe extrapolar la volatilidad diaria de los títulos de renta fija de largo plazo hasta la duración del título, pues debido a que los pagos de renta fija se reciben con (casi) certeza, existe autocorrelación negativa en los retornos. Tampoco se debe extrapolar la volatilidad diaria del valor cuota de la cartera accionaria, pues Campbell y Viceira (2002), entre otros, demostraron que la volatilidad de las acciones para horizontes de una o más décadas es notoriamente inferior a la volatilidad con datos anuales. En particular, estos autores muestran en su figura 4.2 en p. 109 que la desviación estándar anualizada de retorno accionario cae desde 18\% para horizonte de un año, a $13 \%$ para horizontes de 50 años (que es el relevante para pensiones). (b) Omite la correlación positiva entre rentabilidad y nivel de la pensión mínima que se observa a plazos de 5 a 10 años: si al país le va mal, la rentabilidad empeora, pero los salarios reales y la posición fiscal también lo hacen, llevando al sistema político a reducir el crecimiento del monto real de la pensión mínima. La nota 7 de Zurita (1994) menciona otros factores que afectan la volatilidad estimada.

${ }^{11}$ Ellos suponen que el PIB real crecerá a 5,5\% anual en 2004-2010 y a 5,0\% anual en 2011-2020. El PIB de 2004 fue \$ 57.357 millones de pesos. 
El Fondo Monetario Internacional publicó en 2005 su propia proyección, utilizando algunos resultados de la encuesta ya citada. El gasto fiscal esperado en pensión mínima del SCI, para el período 2020-2030, alcanza a 0,30\% del PIB, cifra dentro del rango propuesto por Wagner (1991).

\section{b) Subsidio de pensión mínima en el sistema antiguo}

El “déficit operacional” del sistema antiguo alcanzó a 2,70\% del PIB en 2004 (FMI, 2005). El resultado de la subsección anterior atribuye al subsidio de pensión mínima a pensionados del sistema antiguo el 11,5\% del déficit operacional $(=0,31 / 2,70)$ en el escenario medio. El resto del déficit operacional es gasto en las pensiones fórmula, de reparación y de exonerados.

También estima el FMI (2005) el gasto fiscal en "déficit operacional” en el sistema antiguo, para los años 2020-2030, en 0,80\% del PIB de ese momento.

Es incierto cuál será la participación del gasto fiscal en subsidio de pensión mínima dentro del déficit operacional del sistema antiguo en el período 2020-2030. Por una parte, es posible que los beneficiarios de subsidio de pensión mínima en el sistema antiguo sean en promedio más jóvenes que los beneficiarios de pensiones fórmula. Eso ocurriría si estuviera aumentando la proporción de los recién pensionados en el INP que recién reunieron los requisitos de cotización para acceder al subsidio de pensión mínima, pero son mayores de 60M/65H años de edad. Además, el monto de la pensión mínima sube con el salario real e incluso más rápido, acercándose su gasto a la tasa de variación del PIB, mientras que el gasto en pensiones fórmula se reajusta por inflación solamente y disminuye en relación al PIB. Por otro lado, la esperanza de vida de los beneficiarios de pensión mínima puede ser menor que la de quienes reciben pensiones fórmula, porque han sido más pobres toda la vida y han tenido peor nutrición y atención médica.

Mostraremos dos escenarios. En la "estimación baja”, la participación del gasto fiscal en pensión mínima dentro del déficit operacional se mantiene en la cifra media para 2004, que es $11,5 \%$. En ese caso el gasto fiscal proyectado es 0,8\% $\times 0,115=0,092 \%$ del PIB. En cambio, en la "estimación alta” supondremos que domina una eventual menor edad promedio de los beneficiarios de pensión mínima en el INP, de forma que el gasto en los beneficiarios de pensiones fórmula se diluye al $4 \%$ real anual como proporción del PIB. En este caso la participación del gasto en subsidio de pensión mínima dentro del déficit operacional del sistema antiguo se duplica hasta 
23\% en el año 2025 (año central). Esta proporción implica que el gasto fiscal en pensión mínima del sistema antiguo será 0,184\% del PIB en 2020-30.

\section{c) Pensiones asistenciales para la tercera edad}

El gobierno ha informado que el gasto fiscal en pensiones asistenciales (no contributivas) para 2004 se estima en 0,42\% del PIB. Sin embargo, muchas pensiones asistenciales no llegan a personas de la tercera edad, sino que a discapacitados, deficientes mentales y otros menores de 65 años. Los datos de Riesco (2005) y Dirección de Presupuestos (2006b) indican que los beneficiarios de pensiones asistenciales en la tercera edad son unos 240 mil de los 451 mil beneficiarios, es decir un 53\%. Incorporando esta corrección, el gasto fiscal en pensiones asistenciales en 2004 habría sido $0,22 \%$ del PIB.

Para 2025, el FMI (2005) proyectó un gasto en pensiones asistenciales de $0,60 \%$ del PIB. Suponiendo que todo este aumento respecto a la cifra de 2004 se debe al efecto del envejecimiento de la población, y que el monto destinado a menores de 65 años se mantiene en 0,20\% del PIB, entonces habría que rebajar la proyección del FMI $(2005)$ a $(0,60-0,20)=0,40 \%$ del PIB en 2025.

El Cuadro $\mathrm{N}^{\circ} 3$ muestra que el escenario (bajo o alto) no influye mucho sobre la tendencia para el gasto fiscal total en pensiones solidarias. En este rango de escenarios, el gasto fiscal total en pensiones mínimas se incrementará entre 0 y 0,09\% del PIB durante los próximos 20 años. El Cuadro $\mathrm{N}^{\circ} 3$ también muestra que la exclusión del gasto fiscal en subsidio de pensión mínima del sistema antiguo implicaría proyectar un incremento en el gasto fiscal en pensión mínima de 0,17\% del PIB (escenario central), es decir más del triple de lo proyectado considerando la desaparición gradual del sistema antiguo.

El gasto en pensiones asistenciales se incrementará en 0,18\% del PIB. La tasa de aumento del gasto fiscal total en pensiones mínimas (12\% en el escenario promedio) es mucho menor que la tasa de aumento del gasto en pensiones asistenciales (81\%). Es posible que ello se explique por la mejor rentabilidad del sistema de capitalización individual y por el gradual incremento de densidad de cotizaciones que ha permitido la mayor eficiencia y equidad de sus beneficios.

Sumando, el conjunto de los gastos del pilar solidario aumenta su participación en el PIB en 37\% en 20 años para un escenario central (promedio del bajo y alto), como corresponde esperar del proceso de envejecimiento que se cree sufrirá la sociedad chilena. 
CUADRO N N $^{\circ}$ TENDENCIA EN EL GASTO FISCAL TOTAL EN PENSIONES SOLIDARIAS: CHILE 2004-2025

(\% del PIB de cada año; no considera el alza de 10\% de abril de 2006)

\begin{tabular}{l|c|c|c}
\hline & $\begin{array}{c}\text { Año 2004 } \\
\text { (esc. central) }\end{array}$ & \multicolumn{2}{|c}{$\begin{array}{c}2020-2030 \\
\text { (sin alza de 10\% en 2006) }\end{array}$} \\
\hline Pensión mínima en sist. capit. individual & $0,08 \%$ & \multicolumn{2}{|c}{$0,30 \%$} \\
\hline & & $\begin{array}{c}\text { Estimación } \\
\text { baja }\end{array}$ & $\begin{array}{c}\text { Estimación } \\
\text { alta }\end{array}$ \\
\hline Pensión mínima en sistema antiguo & $\mathbf{0 , 3 1 \%}$ & $\mathbf{0 , 0 9 \%}$ & $\mathbf{0 , 1 8 \%}$ \\
\hline Total subsidio pensión mínima & $0,39 \%$ & $0,39 \%$ \\
\hline $\begin{array}{l}\text { Pensiones asistenciales ancianos } \\
\text { Total pensiones solidarias }\end{array}$ & $0,22 \%$ & \multicolumn{2}{|c}{$0,40 \%$} \\
\hline $\begin{array}{l}\text { Memorándum: } \\
\text { "Déficit operacional” depurado de } \\
\text { subsidios de pensión mínima en } \\
\text { sist. antiguo }\end{array}$ & $\mathbf{0 , 6 1 \%}$ & $\mathbf{0 , 7 9 \%}$ \\
\hline \begin{tabular}{l} 
Gasto en bonos de reconocimiento \\
\hline
\end{tabular} & $1,13 \%$ & \multicolumn{2}{|c}{$0, \mathbf{2 8 \%}$} \\
\hline
\end{tabular}

Fuente: Tabla 4 en FMI (2005) para cifras en letra normal; este estudio para cifras en cursiva.

Sin embargo, la magnitud absoluta del incremento del gasto fiscal total en el pilar solidario es apenas 0,23\% del PIB (escenario central) en 20 años. Esta cifra es pequeña dentro del gasto global del gobierno central, que alcanzó a 20,2\% del PIB en 2004. Sería perfectamente posible financiar esta cifra aunque no existiera el "dividendo por término de la transición de la reforma de 1980”, que en las próximas dos décadas reducirá el gasto fiscal global.

Estas cifras descartan la siguiente afirmación del Poder Ejecutivo (2006), que es parte central del diagnóstico presentado a la Comisión de Reforma Previsional: "La envergadura de los compromisos fiscales futuros generados por el sistema de pensiones confirma la necesidad de un rediseño (para) contar con (un) financiamiento sostenible” (Poder Ejecutivo, 2006).

Por el contrario, el costo total del pilar solidario sube en forma moderada. Y como se ilustra en la sección 5, el grueso de los compromisos es generado por decisiones políticas. Un rediseño se justifica, pero por las inequidades e ineficiencias que mantiene el pilar solidario desde hace muchos años, no por insustentabilidad fiscal. 
Para uso en la sección 5, entregamos también una estimación del valor presente esperado del incremento de gasto. Se trata de un incremento de $0,23 \%$ del PIB en 20 años. Supondremos además, con fines de ilustración, que ese incremento continúa hasta duplicarse en 40 años, pero que de ahí en adelante el incremento se mantiene estable en 0,46\% del PIB. Usamos como tasa de descuento una diferencia $\mathrm{r}$ - g igual a $2 \%$ anual, donde $\mathrm{r}$ es la tasa real de descuento de largo plazo y g es la tasa de crecimiento del PIB y de la recaudación fiscal en el largo plazo. El valor presente esperado del incremento de gasto resulta ser $10,1 \%$ del $\mathrm{PIB}^{12}$.

La última línea del Cuadro $\mathrm{N}^{\circ} 3$ revela que el “dividendo por término de la transición" correcto es 2,39 - 0,67 $=1,72 \%$ del PIB por concepto de déficit operacional, más 1,13-0,10 = 1,03\% del PIB por concepto de bonos de reconocimiento. El total del “dividendo por término de la transición” alcanza a 2,75\% del PIB. Chile enfrenta el problema de qué hacer con estos recursos, que son permanentes: ¿bajar impuestos o iniciar otros programas de gasto fiscal? En cualquier caso, el incremento esperado de gasto en subsidios del pilar solidario del sistema de pensiones es muy inferior a esta suma.

Esto tiene relación con otra afirmación de la Dirección de Presupuestos (2006a): “Además, no existen antecedentes que permitan anticipar que tales tendencias (alto costo fiscal) puedan revertirse en el tiempo, sino que más bien es altamente probable que se profundicen (...)”. O sea, el gobierno no toma en cuenta el “dividendo por término de la transición”, que el Cuadro $\mathrm{N}^{\circ} 3$ estima en 2,75\% del PIB.

\section{Atribución errónea de gastos a la reforma de $\mathbf{1 9 8 0}$}

En el diagnóstico ofrecido a la Comisión de Reforma Previsional, el Poder Ejecutivo (2006) sostiene que "el déficit total del sistema de pensiones entre 2005 y 2010 alcanzará a 4,8\% del PIB, superando ampliamente las expectativas iniciales respecto de los efectos del proceso de reforma previsional (de 1980)”. Además, la Dirección de Presupuestos (2006a) afirma que "El efecto fiscal de la transición previsional (...) ha sido elevado y constituye una de las experiencias más costosas en esta materia en América Latina”.

\subsection{No corresponde atribuir el gasto en programas no reformados en 1980}

Según el mismo Poder Ejecutivo (2006), el déficit en las pensiones de carabineros, gendarmes y militares alcanzará a 1,3\% del PIB. Esto no puede

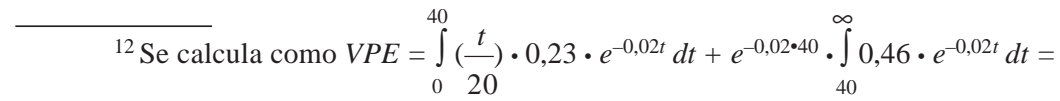
$(5,5+4,6) \%$ del PIB. 
atribuirse a la reforma de 1980, porque estos regímenes de pensión no fueron reformados en esa oportunidad ${ }^{13}$. La reforma de 1980 afectó solamente las pensiones civiles.

Como el Pilar Solidario tampoco fue reformado en 1980, también hay que restar el gasto en pensiones asistenciales y subsidios de pensión mínima que hace el INP. La suma de los gastos permanentes en el Pilar Solidario para el año 2025 es predicha por el mismo Poder Ejecutivo (2006) en 0,4\% del PIB en pensiones asistenciales, más $0,12 \%$ del PIB en pensiones mínimas del sistema nuevo. Según las cifras de la sección 3, a ello hay que sumar 0,38\% del PIB en pensiones mínimas del sistema antiguo.

$\mathrm{Al}$ analizar datos de varios años, tampoco corresponde atribuir a la reforma de 1980 los aumentos reales de pensiones mínimas. Ejemplos son el aumento real de 5\% de 1995 y la creación en 2004 de un nuevo programa que incrementó en 6,3\% las pensiones mínimas para los beneficiarios que cumplan 75 años $^{14}$. Tampoco corresponde atribuir a la reforma de 1980 el costo fiscal del Bono de Invierno de 1998, el del bono de \$ 10.000 de 2004, ni el del bono de \$18.000 de 2006.

Una vez limpiado el costo de los programas permanentes no reformados en 1980, el déficit de pensiones civiles no solidarias queda en a lo más 2,6\% del PIB entre 2005 y 2010. Esta cifra es 46\% menor que la citada por el Poder Ejecutivo (2006).

\subsection{Atribuye a la reforma el costo de aumentos posteriores a 1981}

¿Cuánto del déficit residual de 2,6\% del PIB entre 2005 y 2010 fue causado por la reforma de 1980? Ortúzar (1986), resumiendo un estudio realizado en Odeplan, reporta por primera vez una medición del impacto fiscal de la reforma de 1980 basado en el déficit de caja del INP. Define este déficit como la diferencia entre gasto en pensiones e ingresos por cotizaciones en el INP. Esta diferencia fue llamada "déficit operacional del sistema antiguo”. A ella agregó el egreso de caja por Bonos de Reconocimiento (sección 4.5), para formar el impacto fiscal total de la reforma.

Sin embargo, este "déficit operacional” atribuye a esa reforma de 1980 el costo de aumentos posteriores a 1981 para las pensiones del siste-

${ }^{13}$ Los sistemas de previsión para militares y policías, en todo el mundo, pagan pensiones contingentes al cumplimiento de una permanencia mínima que permite a su empleador recuperar el costo de entrenarlos. Los sistemas contributivos, sean AFP o INP, no pueden pagar pensiones contingentes sin violar su objetivo principal, que es financiar pensiones proporcionales al nivel de ingreso recibido en la vida laboral.

${ }^{14} \mathrm{El}$ incremento para pensionados mayores de 70 años (de 9,3\% respecto de los menores de 70 años) fue creado por el D.L. No 3.360 de 1980. 
ma antiguo, que son adicionales a los aumentos de gasto que generan automáticamente las fórmulas de beneficio del sistema antiguo.

Para aclarar este punto, supongamos el siguiente escenario contrafactual: ninguna ley modifica el sistema antiguo desde 1980 en adelante, y el tamaño de cada cohorte de afiliados es constante en el tiempo. En ese escenario, el gasto anual en pensiones civiles del INP sin subsidios habría crecido, a una tasa relacionada con el aumento de los salarios reales en la economía (empujados a su vez por la absorción de nuevas tecnologías productivas). Esto se debe a que las fórmulas de beneficio del sistema antiguo determinan la pensión como una proporción fija de un "salario base”, y a que éste crece a lo largo de los años en la medida en que el salario real promedio de la economía crezca. Así, cada cohorte de nuevos pensionados tiene una pensión inicial superior a la de la cohorte anterior. Aunque la pensión se reajuste sólo por inflación una vez concedida, el gasto total en pensiones en este sistema antiguo crece automáticamente a la misma velocidad que los “salarios base”. Si además varía el tamaño de las cohortes, el gasto agregado sumará esas variaciones, creciendo en definitiva a la misma tasa que la masa salarial imponible.

Si por encima de ello una o más leyes en el sistema antiguo conceden incrementos generales de pensiones (por encima de la inflación) a personas cuya pensión es mayor que la mínima, el gasto fiscal alcanzará niveles aún más altos en forma duradera. Si bien estos gastos elevan el déficit operacional del INP, es evidente que no fueron causados por la reforma de 1980, sino por las leyes posteriores. A partir de 1987 hubo varios aumentos generales de este tipo. El último de ellos ocurrió en mayo de 2006 y es analizado en la sección 5.4. Inversamente, la lamentable reducción general de pensiones en 10,9\% aplicada en 1985 redujo el déficit del INP, pero ese resultado tampoco puede ser atribuido a la reforma de 1980. La responsabilidad corresponde a la recesión de 1982-1985, a la consiguiente caída en los salarios y en los ingresos tributarios, y a la decisión política de hacer participar a los pensionados de la caída de los salarios.

En conclusión, el indicador "déficit operacional” acumula los impactos fiscales de muchas reformas posteriores a la de 1980, por lo que no es un indicador válido del impacto fiscal de la reforma de 1980. Sin embargo, la Dirección de Presupuestos no ha publicado una descomposición del gasto de pensiones del INP, en aquella parte causada por las leyes vigentes en 1980 para el sistema antiguo, y en la otra parte causada por leyes posteriores. 


\subsection{Confunde el impacto para el INP con el impacto a nivel de todo el fisco}

El “déficit operacional” también es una medida errada del costo fiscal del paso de reparto a capitalización, porque confunde el impacto para el INP con el impacto a nivel de todo el fisco. Para ilustrar esto, imaginemos que los aumentos de pensiones logrados por la ANEF por concepto de "daño previsional” y contenidos en la ley 19.882 de 2003 fueran trasladados al presupuesto de la Subsecretaría de Seguridad Social, descargando el presupuesto del INP. En este caso hipotético, el “déficit previsional” reportado por el INP habría caído, siendo que el efecto fiscal de este traslado es nulo ${ }^{15}$.

Segundo, imaginemos que los legisladores deciden bajar la tasa de cotización al INP y subir a la vez la tasa del IVA, destinando los recursos a cubrir el déficit creado en el INP. El efecto fiscal de esta medida combinada es nulo, si estos cambios de tasa tienen el tamaño relativo correcto. Pero esta reforma eleva el déficit operacional del INP, a pesar de que tiene un efecto fiscal nulo. De nuevo, el indicador de Odeplan confunde el impacto para el INP con el impacto sobre el fisco como un todo.

En realidad existen buenas razones para adoptar la medida indicada en este segundo ejemplo, y ellas tuvieron importancia en la reforma de 1980. Recordemos que el financiamiento por reparto opera sin un fondo de pensiones, y que en su madurez destina la totalidad del flujo de cotizaciones de los afiliados activos a pagar pensiones a la tercera edad. La ausencia de un fondo de pensiones implica que no existen ingresos por rentabilidad ${ }^{16}$. Si el fisco no aporta los recursos faltantes, ellos se obtienen de un impuesto oculto a las remuneraciones cubiertas, que se manifiesta en una tasa de cotización mayor que la que habría cobrado el sistema si hubiera estado capitalizado y hubiera tenido ingresos por rentabilidad, para un mismo nivel de beneficios. El fondo de pensiones ausente fue gastado hace muchas décadas en subsidios para los ancianos y enfermos de esa época, en la forma de beneficios libres del requisito de tener historias completas de cotización.

Como se respeta el compromiso de pagar pensiones a quienes cotizaron en esa época, se creó una “deuda histórica”, no registrada pero real.

\footnotetext{
${ }^{15}$ Del mismo modo, si el subsidio de pensión mínima para Carabineros, Gendarmería y Fuerzas Armadas fuera trasladado al presupuesto del Ministerio de Defensa, el déficit del INP caería, pero el déficit fiscal no cambiaría.

${ }^{16}$ Estrictamente, los recursos que faltan son la parte del ingreso por intereses que excede a la parte que debe sumarse al fondo de pensiones para cubrir los pasivos con los afiliados, que a su vez crecen con la masa salarial cubierta (ver ecuación (8.12) en Valdés 2002, p. 417).
} 
Esa deuda histórica fue creciendo a medida que el financiamiento del sistema antiguo se movió hacia reparto. Esta deuda histórica puede ser trasladada de generación en generación a través del mecanismo del reparto, si el fisco no aporta recursos y obliga al sistema antiguo a "autofinanciarse”. En ese caso la deuda histórica es respaldada con el valor presente de la recaudación futura del impuesto oculto a las remuneraciones cubiertas (Geanokoplos et al., 1998; Sinn, 2000; Valdés, 2005).

En todo sistema de pensiones financiado por reparto puro que no reciba aportes fiscales suficientes, la tasa de cotización contiene un impuesto oculto sobre la remuneración del trabajo cubierto. Este impuesto se define como el valor presente de los intereses que ganaría cada cotización si fuera invertida en un portfolio financiero diversificado, entre la fecha en que se realiza y la fecha en que se paga de vuelta al afiliado en forma de pensión $^{17}$. El impuesto oculto es con frecuencia entre un cuarto y la mitad de la tasa de cotización requerida por el reparto puro (Sinn, 2000).

Si el sistema de pensiones es financieramente autónomo, el impuesto oculto respalda por sí solo la deuda histórica. Existe otro caso donde el sistema recibe aportes fiscales permanentes, permitiendo que la tasa de cotización contenga un impuesto oculto menor. Si el aporte fiscal fuera suficientemente grande, estaría libre del impuesto oculto y la deuda histórica estaría respaldada por impuestos generales y austeridad en el gasto público.

En principio, la obligación de servir la deuda histórica alcanza a todos los ciudadanos, independientemente de cuál sea el método de financiamiento de las pensiones elegido hoy. No hay razón para que su servicio ocurra por medio de impuestos a las remuneraciones cubiertas. Por el contrario, es preferible servir la deuda histórica con impuestos generales, porque provocan menos distorsiones en la asignación de recursos y porque son más equitativos al gravar a los dueños del capital y a los trabajadores independientes (no cubiertos). Si el tamaño del gasto público fuera eficiente, sería aún mejor servir parte de la deuda histórica con austeridad en los gastos fiscales y el resto con mayores impuestos generales.

Por esto, se recomienda reformar los sistemas de reparto maduros y financieramente autónomos, para optimizar los tributos. Una manera de acercarse a eso es eximir del impuesto oculto a grupos o segmentos de cotizantes, sea reduciéndoles la tasa de cotización o subiéndoles los benefi-

${ }^{17}$ Más exactamente, el impuesto oculto responde a una diferencia de intereses. Esta diferencia es la tasa de rentabilidad esperada de la inversión en un portfolio diversificado, menos la tasa interna de retorno del reparto puro, que es la tasa de crecimiento de la masa de remuneraciones imponibles. Esta diferencia es positiva en el largo plazo, para un mismo riesgo, pues de lo contrario habría oportunidades de arbitraje en el mercado de capitales. 
cios. El aporte fiscal requerido se financiaría elevando los impuestos generales o con austeridad en el gasto fiscal. Aunque esta reforma elevaría el “déficit operacional” del INP, tendría un efecto nulo a nivel de todo el fisco. Además sería ventajosa porque aumentaría la eficiencia y la equidad.

Sin embargo, al eximir del impuesto oculto a determinados segmentos de afiliados, se los beneficia con recursos reales. Este beneficio puede tomar la forma de un aumento de salario líquido. En la reforma de 1980 el beneficiado era aquel que decidiera cambiarse al sistema nuevo. En principio, este criterio pudo haber estado lejos de respetar los principios de equidad y eficiencia. Ésta es una crítica importante a la reforma de 1980, pero no tiene relación alguna con el déficit de la transición (Valdés 2002, pp. 559561).

La reforma de 1980 no incluyó ajustes explícitos de impuestos ni de gasto público ${ }^{18}$. Según el director de Presupuestos de la época, la reforma se financió destinando una parte del superávit fiscal de 5,0\% del PIB, que el fisco había alcanzado gracias a que el crecimiento rápido de 1976-1980 elevó los ingresos tributarios y a que el gobierno mantuvo cierta austeridad, en el sentido de evitar que los gastos crecieran tan rápido como los ingresos (Diamond y Valdés-Prieto, 1994). Las propias autoridades de la época declararon que uno de los objetivos de la reforma de 1980 era bajar los impuestos al trabajo cubierto, para lo cual bajarían la tasa de cotización y cubrirían la diferencia con fondos generales.

Basta lo dicho hasta aquí para concluir que el indicador “déficit operacional del INP” no mide correctamente el impacto fiscal de la reforma de 1980, en aquel componente que redujo el impuesto al trabajo cubierto. Este error nació en 1986 en Odeplan, y fue heredado por quienes aceptaron su metodología, por ejemplo Diamond y Valdés-Prieto (1994, p. 280), Holzmann (1997), Arenas y Marcel (1999) ${ }^{19}$, Acuña e Iglesias (2000, p. 466), y Poder Ejecutivo (2006). La literatura económica más reciente lo superó.

\subsection{La forma correcta de medir el costo fiscal del paso de reparto a capitalización}

La capitalización se define como un mecanismo de financiamiento donde la institución previsional acumula derechos de propiedad transables

${ }^{18}$ Hubo una excepción: durante 1981-1984 se aplicó, por seguridad fiscal, un pequeño impuesto al trabajo remunerado de quienes se cambiaron al sistema nuevo y gozaron de un aumento en el salario líquido. Este impuesto transitorio tuvo alta correlación a nivel individual con las transferencias causadas por la reforma misma. Su recaudación no está incluida en la cifra de 1,7\% para 1982.

19 "El desbalance fiscal generado por la reforma de pensiones (de 1980) ha sido sustancial. Entre 1981 y 1998 promedió 5,5\% del PIB” (Arenas y Marcel, 1999, p. 160 al pie de Tabla 3). 
para responder a cada pasivo que asume con sus afiliados. En un sistema financiado por reparto, la adopción de la capitalización provoca un déficit de caja durante la transición. El motivo es que se requiere desviar cotizaciones desde el pago de pensiones, hacia la formación de nuevos fondos de pensiones. Estos fondos pueden ser administrados por la misma institución (el mismo INP) o por instituciones nuevas (como las AFP). Cuando no se obliga a todos los cotizantes a cambiarse al sistema nuevo, sino sólo a las nuevas generaciones, la transición dura aproximadamente 45 años (en Chile duraría desde 1981 hasta 2025, aproximadamente).

¿Cómo se mide el impacto fiscal de una transición cualquiera desde reparto a capitalización? Una aproximación simplista serían las cotizaciones perdidas por el sistema antiguo, en el año inicial de la reforma y como proporción del PIB (ver sección 4.5 para los años posteriores). En efecto, si el sistema antiguo no pierde cotizaciones, no sufre déficit ${ }^{20}$. Este razonamiento condujo a Odeplan al “déficit operacional”. Lamentablemente, olvida que reemplazar el impuesto oculto por impuestos generales tiene un impacto nulo a nivel de todo el fisco.

Conviene presentar otra manera de reemplazar el impuesto oculto por impuestos generales. Ella consiste en permitir a ciertos grupos de afiliados trasladar sus cotizaciones desde el sistema de reparto de origen a otro sistema de destino. En este caso, el sistema de origen sufre dos déficits de caja: el primero es por pérdida de impuesto oculto, y al ser cubierto con un aporte fiscal se evita la insolvencia y se gana una mayor eficiencia tributaria. El segundo déficit es por la pérdida del resto de la cotización, pero no pone en juego la solvencia porque está compensado en valor presente por una reducción igual del pasivo con los afiliados: ahora el sistema debe menos pensiones, en la magnitud indicada por la fórmula de beneficio.

El primer déficit de caja no depende en nada del tipo de financiamiento del sistema de destino, que puede ser capitalización parcial, capitalización pura, o reparto puro. El método de financiamiento en el sistema de origen, en cambio, controla el impacto de este déficit sobre la solvencia del sistema. En efecto, si el sistema de origen hubiera sido financiado por capitalización pura o si aportes fiscales permanentes hubieran reemplazado con anteriori-

${ }^{20}$ Las cotizaciones desviadas deben medirse por diferencia con el escenario contrafactual donde las nuevas generaciones de jóvenes se incorporan al sistema antiguo. Por otro lado, cuando el porcentaje de los cotizantes antiguos que se cambia al nuevo sistema aumenta durante una fase intermedia, existe un efecto contrario pero transitorio: cada ampliación de cobertura del sistema nuevo inicia un nuevo déficit de transición, que se suma al ya existente. Este efecto se dio en Chile durante unos pocos años, pero terminó de operar a mediados de los 80 . 
dad el 100\% del impuesto oculto, este traslado de afiliados no habría afectado la solvencia del sistema que pierde afiliados.

Respecto al segundo déficit de caja, analicemos un traslado de afiliados a un sistema financiado en parte o en todo por capitalización, que no otorga subsidios. Definamos que las cotizaciones "puras" son aquella parte de la cotización que para el afiliado no es impuesto oculto, sino ahorro para la vejez. El tamaño del déficit por desviación de cotizaciones puras sí depende del sistema de financiamiento utilizado por el sistema de destino: a medida que éste usa capitalización en menor grado, requiere menos recursos para formar nuevos fondos de pensiones. El tamaño del déficit de caja por desviación de cotizaciones puras es el único que tiene relación con el aumento en el grado de capitalización. No tiene relación con el tamaño de la deuda histórica.

La conclusión es que el impacto fiscal del paso de reparto a capitalización se mide por los recursos captados por los fondos que se empiezan a acumular en el sistema de destino (Valdés, 2002, pp. 574-586). En cambio, el criterio del "déficit operacional”, que es la pérdida de cotizaciones por parte del sistema de origen, suma un ítem muy distinto: el impacto fiscal de reducir el impuesto oculto.

\section{El caso de la reforma de 1980 en Chile}

Acuña e Iglesias (2000) reportan que en Chile el flujo de cotizaciones captado por el sistema de destino fue 1,7\% del PIB en 1982 y 1,5\% del PIB en 1983, porque ésa fue la recaudación de cotizaciones por parte de los nuevos fondos de pensiones (ver su Cuadro $\mathrm{N}^{0}$ 5, p. 468, línea “Contribuciones”) ${ }^{21}$. El bajo valor para 1983 se explica en parte por la alta tasa de desempleo de ese año, pero eso habría afectado también la recaudación del sistema de origen si no hubiera existido reforma en 1980.

Cuando un afiliado abandonaba al sistema antiguo, éste perdía más que eso, pues perdía también el impuesto oculto. Dicho de otra forma, perdía cotizaciones a su propia tasa, que era $22 \%$. Buena parte de esta tasa era un impuesto oculto a la remuneración, pues esa tasa excedía en mucho al valor presente de los beneficios esperados obtenidos con la cotización (Cheyre, 1988). La reforma de 1980 determinó una tasa de cotización de 14\% para el sistema nuevo. Esta cifra indica, aproximadamente, el monto de la cotización "pura” que se debe ahorrar bajo supuestos conservadores de

${ }^{21}$ La cifra de 1981 fue mucho menor, pues se inicia recién en el mes de mayo (no en enero). El valor del fondo de pensiones a final de 1981, que suma intereses al flujo desviado, fue sólo 0,9\% del PIB. 
rentabilidad, para alcanzar una pensión de monto similar a la del sistema antiguo. La tasa de $14 \%$ estaba libre del impuesto oculto ${ }^{22}$.

En suma, el impacto fiscal inicial del paso de reparto a capitalización se limitó, en 1982, a los recursos captados por los nuevos fondos de pensiones (1,7\% del PIB).

\subsection{Los años posteriores y el Bono de Reconocimiento}

La reforma de 1980 tuvo un componente más: reconocer a quienes contribuyeron en la parte inicial de su vida laboral al sistema antiguo, las expectativas de pensión que acumularon en él. Este reconocimiento puede hacerse de varias formas, por ejemplo con pensiones vitalicias parciales, de monto proporcional al período cotizado en el sistema antiguo ${ }^{23}$. El costo fiscal de este reconocimiento es parte del impacto fiscal de la transición de reparto a capitalización, como reconoció correctamente Odeplan.

Si el reconocimiento es hecho con rentas vitalicias parciales, entonces el gasto en este reconocimiento decrece en el tiempo como proporción del PIB, debido a la mortalidad de los afiliados del sistema antiguo. Además, la desviación de cotizaciones puras hacia el sistema nuevo empieza a ser compensada, para el sistema nuevo, por la caída en la pensión adeudada a cada afiliado. Estos dos efectos causan una caída continua en el déficit total ocasionado por el tránsito a capitalización. Estos efectos dominan si la cobertura de cotizaciones no cambia, la edad promedio de afiliación y jubilación no cambian y la fórmula de beneficio no cambia.

Sin embargo, cuando el traslado al sistema nuevo es gradual, cada reducción de afiliados en el sistema antiguo acelera la acumulación de los nuevos fondos de pensiones. Además, la acumulación de fondos nuevos puede acelerarse cuando afiliados trasladados que dejaron de cotizar por

${ }^{22}$ Ambas tasas de cotización incluyen la prima del seguro de invalidez y sobrevivencia y los costos de administración. La diferencia de tasas de ahorro para pensiones continúa siendo cercana a $8 \%$ del salario.

${ }^{23} \mathrm{El}$ "Bono de Reconocimiento" usado en la reforma de 1980 se distingue de otras formas de reconocimiento en que paga la suma de todos los reconocimientos al contado, cuando el beneficiario inicia pensión. El pago al contado adelanta el egreso fiscal. Este adelanto empeora el balance de caja del fisco al principio, a cambio de adelantar también el "dividendo por término de la transición”. El efecto sobre el patrimonio fiscal de este adelantamiento de pagos depende de la diferencia entre la tasa de interés de mercado y la tasa de interés legal del Bono, que es $4 \%$ real por año. En Chile, la tasa legal de $4 \%$ anual fue inferior a la tasa de interés del mercado de largo plazo para bonos del Estado entre 1981 y 2002, pero ha sido superior desde entonces y la actual curva de rendimientos predice que seguirá siendo inferior durante los próximos 20 años. El impacto fiscal de esta diferencia de intereses no parece ser significativo. 
estar desempleados o inactivos, vuelven a cotizar durante un auge. El primer efecto se dio en Chile hasta mediados de los años 80 y el segundo hasta inicios de los 90, y ambos efectos se reflejan en la serie de recaudación de cotizaciones a PIB mostrada por Acuña e Iglesias (2000, p. 468). En 19901992 se dió el máximo de recaudación de cotizaciones en el sistema de AFP para períodos móviles de tres años, que fue 2,26\% del PIB. Sin embargo, esta cifra no considera la mortalidad ni la caída en la pensión adeudada a cada afiliado en el sistema antiguo. No existen estudios que cuantifiquen estos dos efectos. Una aproximación es medir a qué velocidad cae la suma del déficit operacional más el gasto en liquidar bonos de reconocimiento. Según el Poder Ejecutivo (2006, Anexos, Cuadro N² 2), esta caída fue de 0,3 \% del PIB entre 1998 y 2004 (6 años) ${ }^{24}$. Aplicando esta velocidad al período 19811991 (10 años), la caída acumulada es de 0,5\% del PIB. Restando esto del flujo de cotizaciones al sistema de AFP ya citado se encuentra que en el año 1991 el impacto fiscal del paso de reparto a capitalización era 1,76\% del PIB.

Aplicando el mismo procedimiento al año 2005, se encuentra que la caída acumulada es de 1,2\% del PIB. Restando esto del flujo de cotizaciones al sistema de AFP registrado en 2005, que fue $2,4 \%$ del $\mathrm{PIB}^{25}$, se encuentra que el costo fiscal del paso de reparto a capitalización fue sólo 1,2\% del PIB en el año 2005. Una proyección simple para 2008 entrega un impacto fiscal de $1,05 \%$ del PIB.

\section{Conclusión}

El impacto fiscal del tránsito de reparto a capitalización es la captación de fondos por parte de los nuevos fondos de pensiones en el sistema de AFP, menos los efectos de la mortalidad y de la caída en la pensión adeudada a cada afiliado en el sistema antiguo.

Esta cifra fue 1,7\% del PIB en 1982. La estimación gruesa explicada recién indica un costo cercano a 1,76\% en 1991 y a 1,2\% del PIB en 2005. Nuestra proyección para 2008 es 1,05\% del PIB. Esta cifra es 78\% menor que el 4,8\% del PIB proyectado por el Poder Ejecutivo (2006) para 2005-2010.

Con todo, a pesar de nuestras críticas, expresamos consenso con el Poder Ejecutivo (2006) en cuanto a que las cotizaciones desviadas al siste-

${ }^{24}$ Es indispensable evitar los años anteriores a 1998 porque en ellos el déficit operacional subió como porcentaje del PIB. Probablemente ello ocurrió debido a incrementos de pensiones, en especial de pensiones mínimas, asistenciales, bonos de invierno y a la creación de pensiones para exonerados.

${ }^{25}$ Boletín SAFP No 189, pp. 57 y 151, para el salario medio imponible mensual y el número de cotizaciones totales recibidas en octubre (mes con menos estacionalidad). El PIB nominal de 2005 fue 65.549.137 millones de pesos. 
ma nuevo desde 1981 no aumentaron el ahorro nacional, sino que fueron un traslado de recursos del sector público al privado (a los fondos de pensiones). El aporte al ahorro nacional asociado a la reforma de pensiones — dado por el financiamiento de la transición vía aumento del saldo fiscal primario - proviene de la disciplina fiscal y no de la gestión privada del sistema nuevo. Por otro lado, se debe precisar que las ganancias de rentabilidad por diversificación internacional sólo son alcanzables con el financiamiento de capitalización. Además, el origen del “dividendo por término de la transición”, que es el excedente de caja que obtiene el fisco a partir del término del pago de pensiones a cada cohorte de afiliados del sistema antiguo (por fallecimiento) es la austeridad fiscal adoptada en 1976-1980, convertida en permanente al inicio de la reforma de 1980. Esta política no fue elegida en 1990-2006, sino en 1980.

\section{Contabilidad devengada, pasivos fiscales y riesgos fiscales}

En general, se requiere que el fisco lleve contabilidad devengada para que se pueda evaluar correctamente el costo de su generosidad, pues esa contabilidad es la única que obliga a hacer provisiones o reconocer pasivos, según el caso. Ambos deben ser cubiertos con adiciones a los fondos de reserva, pues hacen frente al costo de largo plazo. El costo de caja de esas adiciones a las reservas transparenta a la opinión pública el costo económico verdadero de una medida.

La Dirección de Presupuestos ha tenido logros ejemplares en moverse desde la contabilidad de caja al "balance ajustado” a partir de 2001, pero no llega todavía a una contabilidad devengada. En esta sección argumentamos que ciertos conceptos contables introducidos por la Dirección de Presupuestos en relación con los pasivos fiscales a partir de 2001, mucho antes del auge del cobre, constituyen un retroceso, porque no distinguen adecuadamente entre pasivos contables y riesgos fiscales. Este punto sirve de base para criticar algunos elementos del proyecto de Ley de Responsabilidad Fiscal en la sección 6.

\section{1. ¿Son los gastos futuros en pensión asistencial un pasivo fiscal?}

Según varios informes de la Dirección de Presupuestos (2001 en adelante), respaldados por un artículo conceptual de Arenas y Guzmán (2003), el programa de pensiones asistenciales (PASIS) sería un "pasivo” del fisco chileno, en el sentido contable, es decir un pasivo exigible. Mos- 
traremos que calificar esos gastos futuros de pasivo es incorrecto y que además es un retroceso costoso porque aumenta la probabilidad de que en el futuro el fisco pierda el poco margen de maniobra que posee respecto de ese gasto.

Arenas y Guzmán (2003) sostienen que el Programa de Pensiones Asistenciales (PASIS) sería un "pasivo" del fisco chileno, susceptible de reportarse en su contabilidad como pasivo. Sustentan su afirmación en que este gasto es directo, aunque implícito. El calificativo de “directo” significa que el gasto debe afrontarse en toda circunstancia, en el sentido de que no hay un suceso gatillador para este gasto. El calificativo de "implícito” significa que si bien pagar PASIS no es una obligación establecida en un contrato, es un compromiso moral para con los indigentes ancianos, ya asumido por el sistema político ante la opinión pública.

Mostraremos que estas definiciones no son aceptadas por ningún país ni por ninguna organización de expertos fiscales, incluyendo el Fondo Monetario Internacional y la OCDE, y que ello ocurre por sólidas razones.

\section{Crítica 1: Es contrario a las normas contables generalmente aceptadas}

El apunte del curso Contabilidad I en la Universidad Católica, de los profesores Julio Gálvez y Vivian Clarke, define pasivo contable como ${ }^{26}$ :

Una obligación de la [organización] hacia terceras personas, de pagos en efectivo, en bienes o servicios, por un monto posible de cuantificar con razonable grado de precisión, con vencimiento en un momento futuro razonablemente definido.

Se deduce que si el deudor está autorizado a manejar el plazo y/o el monto de la obligación, entonces el plazo no podría ser "razonablemente definido” ni el monto ser “cuantificado” con razonable grado de precisión. En ese caso, aunque exista una obligación en un sentido amplio, e incluso aunque pueda justificarse separar parte del patrimonio bajo la denominación de "reserva", ella no es un pasivo contable ${ }^{27}$.

${ }^{26}$ Gálvez, J. y V. Clarke (varios años), Contabilidad Financiera para la Dirección de Empresas, Apunte Escuela de Administración de la Pontificia Universidad Católica de Chile, Santiago.

${ }^{27}$ Un ejemplo de esto último lo constituyó la deuda subordinada de los bancos, que hasta mediados de los años 90 se pagaba al ritmo de las utilidades que tuviera el banco. Esto creaba incentivos a no tenerlas, con el fin de postergar el plazo de pago. Por este mismo motivo, esta deuda no se reportaba en el balance. El saldo pendiente está fuera del balance, en una nota a los estados financieros. Agradezco este ejemplo al profesor Gustavo Maturana. 
En caso de la pensión asistencial, su gasto futuro tiene las siguientes propiedades: el monto de la pensión nominal mensual está autorizado en la Ley de Presupuesto, que es anual (expira a final de año). Los gastos más lejanos en el tiempo no están autorizados hasta que los legisladores aprueben las leyes de presupuestos de los años respectivos.

En el pasado, las sucesivas leyes de presupuestos y otras leyes han dictado reajustes de magnitud variable en relación a la variación del índice de salarios medios. Ese margen de maniobra puede ser valioso para preservar la solvencia fiscal, sobre todo en recesiones, cuando caen los ingresos fiscales. Además, las leyes también han modificado muchas veces los requisitos para acceder a este beneficio ${ }^{28}$. Se concluye que en este caso el pagador, que es el Estado, puede manejar el monto del pago futuro y sus condiciones de acceso. Ello implica que esos gastos futuros esperados no son un pasivo, según las normas de contabilidad generalmente aceptadas.

Pero ¿no existe acaso un compromiso moral y social para con los ancianos en pobreza, de ayudarlos con la PASIS? Claro que sí, pero ese compromiso moral no especifica un monto que pueda ser exigido por un anciano ante un tribunal si no lo recibe en forma oportuna e íntegra. Ese compromiso moral está en similares condiciones que el gasto público futuro en salud, donde también se ha propuesto calificar a esos subsidios como un “derecho ciudadano”, incluso de acceso universal. Aunque una ley califique de "derecho ciudadano" a los subsidios de salud, ellos no serán un verdadero pasivo fiscal hasta que se entregue, a cada posible beneficiario, un derecho de propiedad sobre aquél.

Un derecho de propiedad incluye, al menos, la expectativa fundada de ganar una demanda al fisco en caso de no entrega oportuna y completa. Desde 2004 el plan AUGE parece ofrecer esto respecto de una lista finita de tratamientos. Sin embargo, hay matices. Es posible que el protocolo del AUGE todavía deje espacios al Estado para reducir la calidad del servicio, aunque ése no fue el espíritu de lo anunciado a la ciudadanía. Además, un verdadero pasivo también incluye el derecho a exigir compensación por expropiación en caso de que alguna nueva ley reduzca el beneficio o lo grave con tasas o cargas discriminatorias en comparación con otras rentas. No es claro que este segundo requisito se cumpla respecto a los subsidios previstos en el plan AUGE. En efecto, si una nueva ley o norma retirara una enfermedad de la lista de patologías cubiertas por el AUGE, o si el Estado rebajara el costo estimado de la atención por debajo del costo, una persona que quede sin atención debido a estos cambios normativos ¿ganaría una

${ }^{28}$ Por ejemplo, en abril de 2006, el gobierno de Bachelet eliminó la lista de espera para el cupo de la pensión asistencial. 
compensación monetaria accionando en tribunales contra el fisco? Es probable que no.

La diferencia de naturaleza entre los pasivos contables y las obligaciones morales tiene una consecuencia: al admitir el deudor que tiene un pasivo, eleva la probabilidad de que en el futuro los tribunales lo obliguen a pagar compensación al beneficiario, por ejemplo cuando una nueva ley o norma reduzca el valor esperado del desembolso.

También hay matices en la obligación moral de continuar la entrega de subsidios. El acceso a la PASIS depende de requisitos, que pueden variar en el tiempo con nueva legislación y con la rigurosidad de su implementación. Por ejemplo, una vez que deja de ser necesario reevaluar condiciones de pobreza cada tres años, la obligación moral de continuar pagándola aumenta; así como también cuando se eliminan los cupos. Estos matices afectan la magnitud del "riesgo fiscal”. La diferencia es que al estar el riesgo fiscal fuera de balance, éste no puede ser presentado al tribunal como "prueba” de que el fisco adeuda fondos.

La situación es entonces la siguiente: si se concede un derecho de propiedad sobre los beneficios de pensión asistencial, entonces habrá un pasivo contable. También habrá pasivo fiscal respecto de otros gastos que sean un derecho para el beneficiario. Por ejemplo, en Colombia el derecho constitucional a la vida ha permitido que algunos jueces obliguen al fisco a pagar alimentos a niños y adultos pobres. En principio, podría crearse también un "derecho ciudadano a la defensa nacional y a la seguridad personal”, lo cual convertiría a los gastos futuros en defensa y policía en otro pasivo fiscal. Esto muestra que el concepto de "derecho ciudadano", de tomarse en forma literal por los jueces, puede llegar a imponer costos y rigideces muy significativos.

La alternativa es mantener la flexibilidad tradicional, y sostener el compromiso moral de ayuda a los más pobres en un consenso social más que en contratos y derechos de propiedad. En ese caso, aunque un donatario tenga una expectativa de recibir una donación positiva, su monto exacto es decidido en el año correspondiente por el donante (por las autoridades, en representación de la ciudadanía), considerando el conjunto de la situación económica. Como una mera expectativa de recibir una donación no es un pasivo exigible, entonces los pagos futuros de PASIS no son deuda fiscal.

Sin embargo, los "riesgos fiscales" pueden reportarse como "provisiones”, definidas como cuentas segregadas dentro del patrimonio fiscal. Las provisiones no son exigibles, a diferencia de los pasivos. Para determinar provisiones es necesario cuantificar los "riesgos fiscales" originados en 
compromisos morales y sociales. También puede justificarse acumular reservas para respaldar las provisiones originadas en riesgos fiscales.

Un buen motivo para constituir provisiones es que resulta ineficiente e injusto dejar a las futuras generaciones la tarea de subir los impuestos o bajar otros gastos para hacer frente a los aumentos de gasto previsibles que hemos llamado “riesgos fiscales”. La acumulación de reservas para crear un ingreso futuro por rendimientos o rentabilidades puede distribuir esa carga en forma más suave en el tiempo, evitando ineficiencias y facilitando ajustes graduales y preanunciados a las edades de elegibilidad y porcentajes de copago.

En España se obliga a las empresas que cargan con el equivalente de un "riesgo fiscal", es decir con obligaciones con un cierto componente de incertidumbre o contingencia en cuanto a su exigibilidad, importe o vencimiento, a realizar una “provisión” o "reserva matemática” al interior de su patrimonio. Cuando la obligación se convierte en cierta en cuanto a todos los aspectos mencionados, se convierte en deuda contable, es decir exigible. Este sistema, que también usan en Chile las compañías de seguros, tiene la virtud de maximizar la transparencia y mejorar la toma de decisiones, sin exponerse a juicios de los beneficiarios.

\section{Crítica 2: Es contrario a la mejor práctica fiscal internacional}

Analizamos en primer lugar el documento de Hana Polackova (1998), funcionaria del Banco Mundial. Éste fue citado por la Dirección de Presupuestos (2001) como aval de su propuesta conceptual de tratar como pasivo al gasto futuro en pensión asistencial. Su lectura muestra que ese documento es cuidadoso en su lenguaje, evitando en todo lo posible el concepto de pasivo, sustituyéndolo en su lugar por la expresión "riesgo fiscal”, y por “pasivo en su sentido amplio”. Para empezar, Polackova (1998, p. 2) precisa en la nota de pie $N^{0} 1$ que según la definición de la Federación Internacional de Contadores (1998):

un pasivo es una obligación presente que tiene forma económica, y que se origina en eventos pasados, cuya cancelación se espera resulte en un egreso de recursos.

En ausencia de derechos de propiedad exigibles por el beneficiario, el gasto esperado no cumple el requisito de ser una obligación, y por tanto no es un pasivo en el sentido contable. Esto es reconocido por Polackova, pues afirma que los gastos esperados futuros en pensiones cuyo monto no es aún exigible "no son un pasivo en el sentido contable estricto” (p. 5). 
Polackova (1998, p. 2) da como ejemplo de "pasivo” a los gastos fiscales esperados en pensiones especificadas por contrato. Aquí se está refiriendo a casos donde existe un contrato, sea de carácter laboral o de otro tipo, que genera derechos de propiedad exigibles por parte del beneficiario contra el pagador. No es el caso de las pensiones asistenciales.

Polackova también afirma que cuando la sociedad sufre de envejecimiento, los gastos esperados futuros en pensiones generan "riesgo fiscal". Notemos que evita usar el vocablo pasivo. Del mismo modo, se refiere al "riesgo fiscal" (no al pasivo) causado por los subsidios de salud en las sociedades sujetas a envejecimiento. Estas precisiones de Polackova permiten cubrir el caso de una sociedad que rejuvenece demográficamente, reconociendo que en ella los gastos en pensiones no generan riesgo fiscal.

El Fondo Monetario Internacional, en su "Manual de Transparencia Fiscal” (2001), reporta que "las obligaciones futuras de pagar pensiones públicas no han sido reconocidas como un pasivo en ningún país que haya adoptado la contabilidad devengada. Sólo los pagos corrientes [dentro del año fiscal] son reconocidos como un pasivo"29.

Al reportar sobre el cumplimiento del gobierno chileno de los estándares y códigos sobre transparecia fiscal, el staff del Fondo Monetario Internacional criticó que los "riesgos fiscales" carecían de un tratamiento sistemático (FMI, 2003, pp. 26-27).

La Ley de Responsabilidad Fiscal de Nueva Zelanda (1994), que ha sido calificada por numerosos autores como una de las mejores en cuanto a práctica fiscal, es decidora. Se puede ver en su último balance que Nueva Zelanda no reconoce ningún pasivo fiscal por concepto de pensiones futuras a pagar por parte del sistema de pensión general para toda la población $^{30}$.

El único pasivo relacionado con pensiones que Nueva Zelanda reporta en su balance fiscal es “GSF Pension Liability”. Su monto se obtiene a partir de los derechos de propiedad que poseen los empleados del Estado en Nueva Zelanda, por concepto de remuneraciones diferidas, sea en la forma de pensiones complementarias (adicionales a las que paga el sistema de pensión general para toda la población), o sustitutivas (la cotización a este plan reemplaza la participación en el régimen general).

29 Ver en http://www.imf.org/external/np/fad/trans/manual/index.htm, Box 8 “Contingent Liabilities, Policy Obligations and Implicit Liabilities”, tercer párrafo. Sin embargo, desde 2002 Suecia publica una estimación del valor presente de pensiones devengadas en su sistema público para la clase media (ATP + Inkomstpension). Sin embargo, no lo reconoce como pasivo exigible.

${ }^{30}$ Ver www.treasury.govt.nz/financialstatements/month/jan06/cfs7jan06.pdf 
Por su parte, la Organización para la Cooperación Económica y el Desarrollo (OCDE) aprobó en 2001 una propuesta de "Buenas Prácticas en Transparencia Presupuestaria”31. Si bien nuestro tema no es la transparencia, ese documento de la OCDE no recomienda reconocer como pasivo fiscal al valor presente esperado de los gastos fiscales futuros en salud ni pensiones, sean asistenciales o no. Ese documento de la OCDE recomienda reconocer como pasivo fiscal solamente a aquél derivado de las promesas de pensión emitidas por el Estado a favor de sus propios empleados, como remuneración diferida.

Sin perjuicio de ello, el mismo documento recomienda que el informe presupuestario anual evalúe la sustentabilidad de largo plazo de las políticas fiscales vigentes, especialmente tomando en cuenta el impacto del envejecimiento de la población. Es decir, recomienda medir los "riesgos fiscales”, sin reconocerlos como pasivo en el balance fiscal.

Crítica 3: Contradice la práctica de la propia Dirección de Presupuestos respecto al bono de reconocimiento

Los bonos de reconocimiento son obligaciones fiscales de pago donde los acreedores poseen derechos de propiedad explícitos, concedidos por la reforma de pensiones de 1980, por concepto de cotizaciones al sistema antiguo más un interés. El dueño vende su bono cuando se pensiona antes de cumplir 65 años los hombres, o 60 años las mujeres. El dueño, sea el trabajador o el inversionista que se lo compró, puede reclamar compensación a los tribunales si el Estado no paga un bono en la fecha prevista. Este estatus es igual al de la deuda pública, y muy superior al de los compromisos previsionales existentes en otros países ${ }^{32}$.

Siguiendo los criterios propuestos por Arenas y Guzmán (2003), el bono de reconocimiento sería sin duda un pasivo fiscal. En efecto, si un programa que genera gastos directos e implícitos fuera un pasivo fiscal, con mayor razón lo sería el bono de reconocimiento, que genera gastos directos y explícitos, respaldados por derechos de propiedad. En el caso de los

${ }^{31}$ Ver www.olis.oecd.org/olis/2000doc.nsf/87fae4004d4fa67ac125685d005300b3/ c125692700623b74c1256a4d005c23be?OpenDocument

${ }^{32}$ Arenas y Gana (2005), p. 14, afirman que las obligaciones de pago por bono de reconocimiento "no son conceptualmente distintas al resto de las obligaciones previsionales existentes en otros países". Eso es incorrecto, porque el grado de protección del derecho de propiedad del beneficiario es mayor en el bono de reconocimiento chileno que en los beneficios "definidos" prometidos por sistemas de reparto tradicionales, que pueden ser modificados cambiando la ley que especifica la fórmula de beneficio, sin compensación. 
bonos de reconocimiento, la mejor práctica internacional estaría de acuerdo con calificarlo como pasivo, debido a los derechos de propiedad en favor del acreedor.

Sin embargo, la Dirección de Presupuestos excluye el stock de bonos de reconocimiento no liquidados (por pagar) de la cifra para la deuda fiscal, contradiciendo ambos criterios. No estamos discutiendo la transparencia de la información fiscal, porque el monto de la deuda por bono de reconocimiento está disponible en un anexo estadístico de gran precisión. El punto es otro: ¿es lógico que los bonos de reconocimiento se reporten fuera de balance y que los gastos esperados futuros por pensión asistencial se reporten dentro del balance, como pasivos exigibles? Aunque fuera preferible dejarlos a ambos fuera del balance, la combinación elegida contradice a Arenas y Guzmán (2003).

En resumen, esta sección establece que el concepto propuesto por Arenas y Guzmán (2003), en cuanto a que el gasto futuro en pensión asistencial (PASIS) sería un pasivo fiscal exigible, no debería guiar la política chilena de pensiones ni la política fiscal.

\subsection{El subsidio de pensión mínima tampoco es un pasivo fiscal}

En el subsidio de pensión mínima tampoco se cumple el requisito de que el beneficiario esté protegido por derechos de propiedad. En efecto, el monto de este egreso fiscal depende de decisiones unilaterales del Estado pagador, pues los legisladores ajustan el monto de la pensión mínima cada año, de la siguiente forma:

a) Reajuste por inflación del IPC. Este reajuste es automático desde que así lo dispuso el art. 14 del D. L. No 2.448. de 1979. La tasa de reajuste es la inflación acumulada en los últimos doce meses, o 15\%, cualquiera sea el que ocurra antes. Esta fórmula de reajuste puede ser modificada por los legisladores.

b) Ajustes reales discrecionales a tasa uniforme, insertos en leyes especiales o en otras leyes (Bennett y Schmidt-Hebbel, 2001).

c) Además, cada año desde 1996 el legislador concede "bonos de invierno" y aguinaldos de fiestas patrias y de navidad en la ley que reajusta los salarios del sector público, de magnitudes importantes pero discrecionales $^{33}$.

${ }^{33}$ Ver por ejemplo la Ley $\mathrm{N}^{\mathrm{0}} 19.917$, publicada en 4 de diciembre de 2003, que concede un bono de invierno por \$ 30.240. La ley análoga de 2004 concedió un bono de invierno de \$31.298. 
La consecuencia de esta discrecionalidad es que en los años en que el salario real baja, las autoridades pueden dejar que el valor real de la pensión mínima caiga levemente y al mismo tiempo caiga menos que los salarios. Además, pueden modificar unilateralmente los requisitos para el subsidio de pensión mínima. Por ambas razones, el gasto fiscal en subsidios de pensión mínima es un "riesgo fiscal”, y no un pasivo fiscal exigible.

Como siempre, hay matices: en la medida en que la denominación de “garantía” a este subsidio, otorgada por primera vez en la reforma de 1980, haya inducido a personas a variar alguna decisión, y eso sea demostrable ante un juez o sea motivo de una movilización política efectiva, el "riesgo fiscal” es mayor. Sin embargo, esta innovación "verbal” no alcanza a crear una garantía exigible ante un tribunal.

El hecho de que la prevalencia de los subsidios de pensión mínima dependa en parte de variables aleatorias exógenas que afectan el cumplimiento de los requisitos, como la densidad de cotización y la rentabilidad de los fondos de pensiones, no altera en nada estas conclusiones. El efecto de estos aspectos es requerir usar modelos de valoración de opciones financieras para cuantificar el gasto fiscal esperado. En este punto la Dirección de Presupuestos realizó un avance muy destacable a partir de 2003, pues publicó estudios del tipo indicado para valorizar estos riesgos fiscales ${ }^{34-35}$.

\subsection{Envejecimiento y pasivos fiscales}

Nada de lo afirmado en la subsección anterior pretende objetar el saludable ejercicio de proyectar el monto de gasto fiscal asociado a los distintos programas del Estado. Esas proyecciones, junto con proyecciones de ingresos fiscales, dan luces sobre los déficits fiscales futuros causados por cambios predecibles desde hoy, como el envejecimiento. Cuando se desea evitar ajustes traumáticos en parámetros como la tasa de cotización,

${ }^{34}$ Otros eventos futuros exógenos que influyen son el nivel de salarios reales cotizados y el precio para la renta vitalicia obtenido al momento de jubilar. Estos factores aleatorios pueden ser valorizados con modelos de opciones (Zurita, 1994, lo hace sólo respecto de la rentabilidad en la fase activa). En el sistema antiguo el egreso fiscal depende también de otras decisiones unilaterales del pagador: los parámetros de la fórmula de beneficio (tasa de reemplazo, número de años de cotización, número e indización de los salarios considerados en el promedio), que pueden ser reformados por los legisladores cuando les parezca conveniente.

${ }^{35}$ Además, en un año dado una fracción mayoritaria del gasto futuro en pensiones mínimas ya no es "contingente", porque la contingencia que lo gatilló ya ocurrió en el pasado (en aquel año en que la pensión autofinanciada resultó por primera vez inferior a la pensión mínima). 
la edad de jubilación y el nivel de las pensiones (la tasa de reemplazo), puede ser conveniente ahorrar hoy y formar un fondo de reserva para cubrir ese déficit futuro. Ése es justamente el camino que han elegido países como Estados Unidos (desde 1983), Canadá (desde 1967), Suecia (desde 1960), Irlanda y Nueva Zelanda.

Hay tres diferencias entre esos esfuerzos y los conceptos propuestos por los informes ya citados: primero, sus definiciones implican que en ausencia de envejecimiento demográfico, e incluso si llegara a darse un rejuvenecimiento demográfico ${ }^{36}$, los subsidios de salud y de pensiones seguirían siendo un pasivo fiscal. En efecto, según esos informes, los gastos fiscales futuros son un pasivo, cualquiera sea la situación demográfica. En cambio, los países citados sólo se preocupan de los déficits fiscales causados por el envejecimiento. Si hubiera rejuvenecimiento demográfico, esos programas lograrían superávit, y esos países gastarían sus fondos de reserva o los destinarían a cubrir otros riesgos fiscales.

Segundo, las definiciones de Arenas y Guzmán (2003) implican que un programa de gasto origina un pasivo fiscal, aunque transfiera recursos en forma perfectamente simétrica por edad del beneficiario. Sería el caso de los gastos en defensa nacional y en justicia. En cambio, la metodología utilizada por los países citados, expresada también en la contabilidad generacional (Kotlikoff, 2004), excluye las transferencias simétricas según la edad del beneficiario, porque su perfil de pagos no es afectado por el envejecimiento.

Tercero, en el caso de los programas de impuesto-gasto, las definiciones criticadas no toman en cuenta el ingreso. En cambio, la metodología usada por esos países sí considera los ingresos del programa. Por ejemplo, en España el programa de pensiones gasta actualmente el 9\% del PIB, pero recauda el 9\% del PIB en cotizaciones (ingreso). Si se creyera que el gasto futuro va a continuar alineado con la recaudación de cotizaciones, el déficit proyectado sería nulo, y nadie propondría crear un fondo de reserva. En cambio, sería prudente crear un fondo de reserva si se proyectara, como ocurre en España, un aumento de gasto en las próximas décadas hasta alcanzar $14 \%$ del PIB, unido a un ingreso por cotizaciones constante en $9 \%$ del PIB.

En cambio, los conceptos criticados implicarían que aunque España no proyectara un déficit, tendría un pasivo fiscal (un stock de deuda exigible) por $(9 /(r-g)) \%$ del PIB, donde $r=$ tasa real de descuento y $g=$ tasa de

${ }^{36}$ Una sociedad puede pasar del envejecimiento al rejuvenecimiento a gran velocidad. Sólo toma 9 meses de espera. Por ejemplo, la tendencia al envejecimiento de EE.UU. fue rota en 1948 por una fuerte alza de la natalidad. 
crecimiento del PIB real. En el caso habitual donde $r=0,02+\mathrm{g}$, el pasivo fiscal español sería $=460 \%$ del PIB, cifra que no corresponde a la realidad.

5.4. Aplicación: el aumento de la pensión mínima de abril de 2006

El aumento de las pensiones mínimas y asistenciales propuesto por el Poder Ejecutivo en abril de 2006 tiene un costo anual para el año 2007 que fue informado al Congreso por la Dirección de Presupuestos. Sin embargo, este costo fue proyectado como constante en términos reales desde allí en adelante. ¿Fue el Congreso informado adecuadamente? No se le informó respecto de la interacción con el envejecimiento, ni con el crecimiento económico.

A continuación ofrecemos una estimación sencilla de dicho efecto. Procedemos en dos etapas. Primero determinamos cuál es el porcentaje de aumento en el costo fiscal del subsidio de pensión mínima que se deriva del alza de $10 \%$ de la pensión mínima. Este cálculo requiere conocer el costo en la situación base, que ya determinamos en la sección 3. En segundo lugar, proyectamos de nuevo el costo fiscal para 20 años más, usando los estudios de otros autores, adaptados al nuevo escenario.

a) Porcentaje de aumento en el gasto fiscal, debido a aumento de abril de 2006

El Anexo 2 encuentra, usando simulación numérica en MAPLE, que si el aumento de $10 \%$ real en la pensión mínima se hubiera realizado en diciembre de 2004, el costo fiscal en el sistema antiguo habría subido 25\% real. Esta cifra no fue informada al Congreso.

El aumento en el número de beneficiarios por vejez e invalidez en el sistema antiguo no explica la fuerte diferencia entre este $25 \%$ de aumento y el 10\% de alza en el monto de la pensión mínima. El aumento en el número de beneficiarios es 6,3\% para los causantes y sólo 0,9\% para las viudas (porque casi todas ellas ya son beneficiarias).

La tasa de aumento en el subsidio medio por beneficiario es 21,7\% para los causantes y 15\% para viudas (ver Anexo 2). La razón es que una proporción importante de beneficiarios recibe un subsidio pequeño en la situación inicial. Por ejemplo, si un pensionado con pensión autofinanciada de \$ 79.000 recibía un subsidio de \$ 1.000 en una situación inicial donde la pensión mínima era \$ 80.000, un aumento en la pensión mínima de 10\% (a \$ 88.000) elevaría el subsidio para esta persona a \$ 9.000. La tasa de aumento del subsidio sería $100 \times(\$ 8.000 / \$ 1.000-1)=800 \%$. Ponderando todos los casos se encuentran las cifras citadas. 
El Anexo 2 encuentra que si el aumento de 10\% en la pensión mínima hubiera ocurrido en 2004, el gasto fiscal en pensiones mínimas del sistema antiguo habría subido de la siguiente forma, con un 90\% de confianza:

CUADRO N N $^{\circ} \quad$ COSTO FISCAL DEL INCREMENTO DE 10\% DE LA PENSIÓN MÍNIMA, EN EL SISTEMA ANTIGUO

(Si hubiera ocurrido en el año 2004)

\begin{tabular}{|c|c|c|c|c|c|}
\hline \multirow[t]{2}{*}{ Grupo } & \multirow{2}{*}{$\begin{array}{c}\text { Escenario } \\
\text { de gasto } \\
\text { inicial } \\
(90 \% \\
\text { confianza) }\end{array}$} & \multirow{2}{*}{$\begin{array}{c}\text { Gasto } \\
\text { fiscal inicial } \\
\text { (miles mill. } \\
\text { \$/año) }\end{array}$} & \multirow{2}{*}{$\begin{array}{l}\text { Aumento de } \\
\text { gasto } \\
\text { (miles mill. } \\
\text { \$/año) }\end{array}$} & \multicolumn{2}{|c|}{$\begin{array}{c}\text { Gasto fiscal anual después } \\
\text { del alza }\end{array}$} \\
\hline & & & & $\begin{array}{l}\text { (miles mill } \\
\text { \$/año) }\end{array}$ & (\% del PIB) \\
\hline Suma de & Bajo & \$ 152.946 & \$ 43.317 & \$ 196.293 & $0,34 \%$ \\
\hline causantes & Medio & \$ 176.445 & \$ 42.717 & \$ 219.162 & $0,38 \%$ \\
\hline y viudas & Alto & \$ 200.695 & $\$ 42.303$ & \$ 242.998 & $0,42 \%$ \\
\hline
\end{tabular}

Fuente: Anexo 2.

El valor absoluto del aumento de gasto para un solo año es conservador en comparación con el monto revelado por la Dirección de Presupuestos en su Informe Financiero No 09 al Congreso (2006). Ese informe estimó este mismo aumento de gasto en \$ 53.235 millones/año, pero en pesos de abril de 2006. Haciendo el ajuste por inflación (entre junio de 2004 y abril de 2006), el aumento según la Dipres habría sido de \$ 50.317 millones en pesos de 2004. Esto es, 17,8\% más que la cifra que emerge de nuestro modelo ${ }^{37}$. Sería útil que la Dirección de Presupuestos revelara su modelo de estimación para contrastarlo con el presentado en este trabajo. No puede descartarse que el gasto fiscal en la situación base no haya sido 0,31\% del PIB, sino 17,8\% más alto, llegando en ese evento a 0,37\% del PIB.

Lo importante no es el aumento absoluto, sino el aumento relativo a la situación base, pues éste último permite proyectar el impacto de largo plazo.

${ }^{37}$ La diferencia es aún mayor, porque el número de beneficiarios de subsidio de pensión mínima en diciembre de 2004, fecha a la que se aplica nuestro modelo, fue 486.713 (según Cuadro $\mathrm{N}^{\circ} 1$ ) y esto es mayor que el número de beneficiarios en junio de 2006, fecha a la que se aplica la proyección de la Dipres, que fue 476.412. Una parte de la diferencia entre los gastos que proyectan estos modelos se debe a diferencias de cobertura. Por ejemplo, nuestro modelo no considera el gasto fiscal en pensiones mínimas de antigüedad, orfandad, exonerados políticos ni reparaciones, y tampoco considera las pensiones mínimas de las Fuerzas Armadas, de Carabineros y de inválidos de accidentes del trabajo. 
b) Proyección a 20 años plazo del alza de 10\% de abril de 2006

Ahora sabemos que toda la senda de gasto en subsidios de pensión mínima se eleva en cerca de $25 \%$ en el sistema antiguo. Suponemos que se aplica un porcentaje similar para el subsidio de pensión mínima del sistema nuevo. El Cuadro $\mathrm{N}^{0} 5$ usa esta tasa de expansión, en conjunto con las proyecciones del FMI (2005) para determinar el efecto en las proyecciones de gasto.

Lo más incierto es el impacto de las reformas de abril de 2006 en el gasto en pensiones asistenciales. El alza de $10 \%$ en el monto de la pensión asistencial es igual al alza en el costo fiscal del subsidio, debido al diseño de éste. Sin embargo, la reforma de abril de 2006 también eliminó los cupos cuantitativos para acceder a la pensión asistencial. El gobierno se comprometió en el Congreso a otorgar este subsidio a todos los postulantes con menos de 550 puntos en la ficha CAS. A su vez la ficha CAS está siendo reformulada. Las reformas anunciadas indican que en el futuro será más fácil para los postulantes simular falta de ingresos, pues ya no se medirá el ingreso permanente a través de la tenencia de bienes de consumo durable y de vivienda, sino del ingreso autorreportado.

La Dirección de Presupuestos, en su Informe Financiero al Congreso № 09 de 2006, estimó que el número de beneficios de pensión asistencial

CUADRO N ${ }^{\circ}$ 5: $\quad$ PROYECCIÓN DEL GASTO FISCAL TOTAL EN PENSIONES SOLIDARIAS: CHILE 2025

(\% del PIB de cada año; incluye efectos de expansiones de 2006)

\begin{tabular}{|c|c|c|c|}
\hline & $\begin{array}{c}\text { Memo: } \\
\text { Año } 2004\end{array}$ & \multicolumn{2}{|c|}{$\begin{array}{c}\text { 2020-2030 } \\
\text { (con alza de 10\% } \\
\text { y eliminación de cupos en 2006) }\end{array}$} \\
\hline \multirow[t]{2}{*}{$\begin{array}{l}\text { Pensión mínima en sist. } \\
\text { capitalización individual }\end{array}$} & $0,08 \%$ & \multicolumn{2}{|c|}{$0,38 \%$} \\
\hline & & Estimación baja & Estimación alta \\
\hline Pensión mínima en sistema antiguo & $0,31 \%$ & $0,12 \%$ & $0,23 \%$ \\
\hline Total subsidio pensión mínima & $0,39 \%$ & $0,50 \%$ & $0,61 \%$ \\
\hline Pensiones asistenciales ancianos & $0,22 \%$ & \multicolumn{2}{|c|}{$0,46 \%$} \\
\hline Total pensiones solidarias & $0,61 \%$ & $0,96 \%$ & $1,07 \%$ \\
\hline
\end{tabular}

Fuente: Cuadro $\mathrm{N}^{\circ} 3$ más los ajustes indicados en esta sección. 
aumentará en 25 mil, con un costo fiscal anual de \$ 5.400 millones. Tenemos dudas sobre la calidad de esta proyección, pues es menos de la mitad del número de personas en lista de espera según cifras de mediados de $2005^{38}$. El senador Ominami reveló en el Congreso que en 2005 había 65 mil personas en lista de espera para la pensión asistencial, y que en diciembre, mes de elección presidencial, la Dirección de Presupuestos aumentó los cupos en 40 mil. La diferencia es el origen de la cifra de 25 mil utilizada por la Dirección de Presupuestos en la proyección citada.

Nuestra duda sobre la cifra de 25 mil nuevos subsidios tiene dos fundamentos: (a) no considera que la ausencia de cupos estimulará la postulación en el mediano plazo; y (b) no considera que el diseño de la pensión asistencial no fue mejorado para evitar el violento retiro del beneficio que ocurre cuando el afiliado pasa de 549 a 550 puntos CAS. El término de los cupos aumenta fuertemente el incentivo electoral de cada alcalde a ayudar a los postulantes/votantes a quedar por debajo de 550 puntos. La solución a este segundo punto sería un retiro gradual del subsidio, pero ello no fue considerado por la Ley $\mathrm{N}^{\circ} 20.102$.

Nos parece más conservador reconocer que el número de beneficiarios subirá en más de 25.000. Para cubrirnos, supondremos que el número de nuevos beneficiarios será el doble en el mediano plazo (50 mil) y que el 53\% de ellos serán de la tercera edad. Es decir, suponemos que el gasto en pensiones asistenciales para ancianos subirá en $\$ 5.400$ millones al año (el doble de lo implícito en la cifra de Dipres). Combinando este aumento con el aumento de $10 \%$ en el subsidio per cápita, el gasto fiscal en pensiones asistenciales subiría en 15\% respecto al de 2004.

Suponemos también que el nuevo nivel de gasto seguirá creciendo en el futuro en proporción al PIB (levemente más rápido que los salarios medios), lo que implica elevar la cifra prevista para 2025 a 0,46\% del PIB. El Cuadro $\mathrm{N}^{\circ} 5$ reúne todas estas proyecciones.

Ahora se observa un incremento de $66 \%$ en el gasto fiscal como porcentaje del PIB. Esta magnitud duplica el 37\% de aumento obtenido en el Cuadro $\mathrm{N}^{\circ} 3$, que sólo recoge el efecto de otros procesos, como envejecimiento y crecimiento de salarios, excluyendo la reforma de abril de 2006. Se concluye que el gasto fiscal total en pensiones solidarias depende mucho más de decisiones políticas, como la adoptada en abril de 2006, que del envejecimiento demográfico, o de tendencias originadas en la reforma de 1980.

${ }^{38}$ Como el número inicial de beneficiarios es de 451 mil, un incremento de 25 mil sería sólo 5,5\%. 
El incremento absoluto a 20 años plazo es ahora 0,40\% del PIB. Una contabilidad devengada habría informado al Congreso lo siguiente: antes de abril de 2006 se esperaba que el gasto fiscal en pensiones solidarias aumentara en el tiempo, debido al envejecimiento y demás factores considerados por la proyección del FMI (2005). El valor presente esperado de ese incremento era 10,1\% del PIB (ver sección 3.2). Ahora, a partir de abril de 2006, el incremento de gasto fiscal alcanza a 0,40\% del PIB en 20 años. Mantenemos los supuestos de que ese incremento continuará hasta duplicarse en 40 años, y que de ahí en adelante el incremento se mantendrá estable en la cifra alcanzada (ahora 0,80\% del PIB). Mantenemos la tasa de descuento $\mathrm{r}-\mathrm{g}$ igual a $2 \%$ anual. La novedad es que el valor presente esperado del incremento de gasto fiscal sube a $17,6 \%$ del PIB $^{39}$. La diferencia indica que la reforma de abril de 2006 debió haber sido acompañada de una provisión por 7,5\% del PIB $^{40}$. Esta provisión debería ser respaldada constituyendo un fondo de reserva de similar magnitud. Como vemos, los recursos requeridos son similares al superávit fiscal efectivo proyectado para el año 2006. Con esta información, el Congreso podría haber tomado una mejor decisión.

\section{Conclusión: Lecciones para el proyecto de Ley de Responsabilidad Fiscal}

En septiembre de 2005 el gobierno envió al Congreso un proyecto de "Ley de Responsabilidad Fiscal" ${ }^{\text {. }}$. Ese proyecto fue modificado por indicación del gobierno, de fecha 9 de mayo de $2006^{42}$. El proyecto propone crear un "Fondo de Reserva para Pensiones". Esta sección propone modificaciones a la luz de los resultados de las secciones anteriores.

\subsection{Reconocimiento de pasivos fiscales y provisión de "riesgos fiscales"}

Al reconocer los pasivos fiscales, se introduce una visión de "hoja de balance” en las futuras discusiones presupuestarias. Ella sugiere que

${ }^{39}$ Se calcula como VPE $=\int_{0}^{40}\left(\frac{t}{20}\right) \cdot 0,40 \cdot e^{-0,02 t} d t+e^{-0,02 \cdot 40} \cdot \int_{40}^{\infty} 0,80 \cdot e^{-0,02 t} d t=$ $(9,6+8,1) \%$ del PIB.

${ }^{40}$ Hay que agregar el valor presente esperado del nuevo programa que aumenta las pensiones "bajas”, definidas como aquellas superiores a la pensión mínima, pero inferiores a \$ 110.000. Este nuevo programa fue creado en abril de 2006. Como es discriminatorio y fragmenta el pilar solidario, podría originar una espiral de gasto fiscal.

${ }^{41}$ Mensaje No 259-353 a la Cámara de Diputados, 14 de septiembre de 2005.

42 Mensaje 99-354 que retira y hace presente la urgencia simple. 
conviene respaldar los pasivos y las provisiones con fondos de reserva y otros activos rentables (como empresas públicas bien administradas). Aumentar esos fondos de reserva es caro, pues usa recursos que podrían haberse gastado, y ésta es justamente la información que requiere el Congreso para tomar decisiones. La perspectiva de "hoja de balance" también permite mostrar al Congreso que cambiar la edad de elegibilidad y la tasa de copago (gradualmente) permite liberar fondos en el presente, porque se reduce el monto del aumento en las reservas que es necesario financiar.

Si el pasivo o provisión es permanente, los intereses ganados por la reserva solventarán el gasto anual asociado. Estos intereses son ingresos “estructurales". Si el pasivo dura sólo algunas décadas, también se debe liquidar el principal de la reserva para solventar los gastos. En este caso, la parte del egreso de caja que se financia liquidando reservas es una operación "bajo la línea”, que no afecta el balance estructural ejecutado por el gobierno.

Cuando existen pasivos fiscales significativos y ellos son transparentados, la política fiscal prudente se hace evidente: los fondos de reserva deben ser preservados por los futuros gobiernos incluso durante las recesiones. Esto sin perjuicio de que convenga gastar en las recesiones otros fondos de reserva orientados a estabilizar el gasto fiscal.

Con el fin de promover una mejor gestión fiscal, el proyecto de Ley de Responsabilidad Fiscal debería reconocer y encargar la cuantificación de los siguientes pasivos fiscales, adicionales al costo esperado de las garantías contractuales de recaudación concedidas a los concesionarios de obras públicas, que es el único costo que ya ha sido estimado e informado por la Dirección de Presupuestos desde 2003:

a) La deuda fiscal creada al ceder garantías contractuales a los beneficiarios del plan AUGE. Esta deuda debería ser cuantificada y registrada como tal. Si se determina que en realidad los derechos cedidos por el plan AUGE no alcanzan el estatus de derechos de propiedad completo, el gasto fiscal esperado debería ser cuantificado y sumado a otros "riesgos fiscales”.

b) La deuda fiscal que se crearía si la promesa de la Presidenta Bachelet en su discurso del 1 de junio de 2006, respecto a crear una garantía de calidad para la educación, se materializa en ceder derechos patrimoniales exigibles ante los tribunales.

c) Aquellos empleados públicos a quienes su contrato de trabajo ofreció salarios menores que los de mercado en la época de actividad, a cambio de dinero pagado a partir del término del empleo, son acreedores del 
fisco por remuneraciones diferidas. Como muestra el Anexo 3, la OCDE recomienda reconocer este pasivo fiscal en el balance del Estado y reconocer que el pago de esas pensiones constituye amortización de la deuda fiscal respectiva. Por ejemplo, Nueva Zelanda reconoce un pasivo en sus cuentas fiscales, por concepto de remuneraciones diferidas al personal en retiro de sus fuerzas armadas (pensiones). En Chile, gran parte de las pensiones de la Caja de Previsión de la Defensa Nacional y de la Dirección de Previsión de Carabineros son remuneraciones diferidas, cuyo pago amortiza una deuda fiscal. Esa deuda fiscal debería ser reconocida.

El rol de una cuantificación de los "riesgos fiscales" es similar, pero ellos dan origen a provisiones en el patrimonio fiscal o deben ser informados fuera de balance. Como ya se explicó, incorporar los "riesgos fiscales" como pasivos exigibles perjudicaría al fisco. Hasta ahora el gobierno sólo ha proyectado el costo fiscal anual de los subsidios de pensión mínima del sistema nuevo y de pensiones asistenciales, sin determinar el valor presente esperado del incremento sobre el nivel actual de gasto. Recomendamos que esta Ley de Responsabilidad Fiscal obligue al Ministerio de Hacienda a publicar anualmente un nuevo “Informe de Riesgos Fiscales”, adjunto al informe de deuda pública, que incluya al menos las siguientes cifras:

i) El valor presente esperado del incremento del gasto futuro en subsidios a la salud, debido al envejecimiento y a la innovación tecnológica. Por ejemplo, en EE. UU. se ha estimado que el déficit fiscal esperado (gastos menos cotizaciones) por incrementos en los subsidios de salud a los ancianos alcanza a 54 trillones de dólares, cinco veces más que el déficit fiscal análogo por pensiones del sistema Social Security, que es de 11 trillones de dólares (Kotlikoff y Burns, 2004). Las estimaciones recientes para Europa son igualmente alarmantes (Kotlikoff y Hagist, 2005). La ley debería priorizar una proyección afinada de este riesgo fiscal.

ii) El valor presente esperado del incremento en el costo fiscal de los subsidios de pensión mínima del sistema antiguo, del sistema nuevo y de las pensiones asistenciales, debido al envejecimiento y al aumento de salarios reales. Las secciones 3.2 y 5.4 muestran nuestras estimaciones preliminares de esta cifra, pero sin duda ellas pueden ser proyectadas con mayor exactitud.

iii) El valor presente esperado del incremento en el costo fiscal del Programa de Contingencia Contra el Desempleo, que se originará en el aumento en los salarios reales. 


\subsection{Diseño de los fondos de reserva}

Es valiosa la propuesta de crear un Fondo de Estabilización Económica y Social, para recibir el superávit fiscal efectivo. El concepto de "estabilización” indica que el valor de este fondo podrá ser utilizado durante las recesiones hasta agotarlo, financiando déficits fiscales efectivos. Un fondo que absorba fluctuaciones es la contrapartida lógica de centrar la política fiscal en cumplir una meta para el saldo fiscal "estructural”, que supone un precio del cobre y un crecimiento de la recaudación tributaria en sus valores de largo plazo o de tendencia.

Sin embargo, la presencia de pasivos fiscales y de "riesgos fiscales" sugiere la necesidad de un fondo de reserva de carácter permanente. Se podría pensar que el "Fondo de Reserva para Pensiones" previsto en el proyecto de ley cumpliría esta función.

Sin embargo, ello no es así porque el proyecto destina ese fondo de reserva a un fin específico: el gasto de pensiones asistenciales y mínimas del sistema nuevo. La destinación a un fin específico es cuestionable en general. El gasto social para los ancianos pobres es uno de entre muchos gastos sociales, siendo mayor el gasto en salud y más grave la pobreza infantil (la tasa de pobreza entre los menores de 14 años es el triple que entre los mayores de 65, según las encuestas CASEN 2000 y 2003). Los riesgos del fisco chileno son muchos, incluyendo los que afectan a las utilidades de Codelco y los tributos a las mineras privadas de cobre, y los que afectan a los gastos de defensa. Frente a una multiplicidad de riesgos, la teoría económica recomienda considerar sólo el riesgo conjunto o agregado, que depende de la covarianza entre ellos. La ventaja de este enfoque es que toma en cuenta que algunos riesgos fiscales podrían resultar positivos y otros negativos, cancelándose mutuamente a nivel de todo el fisco.

Se podría intentar justificar una destinación específica a pensiones, argumentando la importancia de dotar a los ancianos pobres de prioridad en la asignación del gasto público futuro, en las recesiones, y en períodos largos de bajo crecimiento. En esa óptica, se podría buscar prevenir que algún futuro gobierno aproveche una eventual estrechez fiscal para reducir el monto de los subsidios a los ancianos pobres, que se decide año a año. Por ejemplo, el mensaje del proyecto de Ley de Responsabilidad Fiscal afirma que:

El principio de la regla de política fiscal (...) garantiza (...) estabilidad en el financiamiento de programas sociales prioritarios (...). Por otra parte, en contraposición con lo ocurrido en los [años] ochenta, en que pensiones y otras prestaciones sociales básicas fueron recortadas de acuerdo a la disponibilidad fiscal en situaciones de crisis externa (... ) (p. 10). 
El fin es loable, pero el medio elegido para lograrlo es equivocado. Como se debe respetar la soberanía de los futuros ciudadanos que elegirán a los futuros gobierno, la prioridad para los pobres debe lograrse en forma transparente, por la vía del convencimiento de la opinión pública. La competencia política genera castigos a quienes abandonen esta vía: el Ministro de Hacienda, que en 1985 recortó en forma excesiva el monto real de las pensiones mínimas, podría haber perdido muchos votos en la elección de 1989 debido a esa medida.

Dotar a los pobres de prioridad en la asignación del gasto público futuro no se opone a priorizar la eficiencia, es decir a aprovechar las covarianzas entre riesgos fiscales. Además, el mensaje citado es contradicho por el texto del proyecto, porque las "prestaciones sociales básicas" no están limitadas en Chile a la pensión asistencial y a los subsidios de pensión mínima del sistema nuevo. Existen también otros programas sociales básicos.

En suma, se propone redefinir el fondo de reserva para que cubra los riesgos fiscales y los pasivos fiscales en su conjunto. Ello implica modificar el proyecto para que el destino de los recursos de este fondo sea cubrir los pasivos fiscales que se reconozcan formalmente y los riesgos fiscales cuantificados en el "Informe de Riesgos Fiscales". 


\section{ANEXO 1 \\ ESTIMACIÓN DEL GASTO FISCAL \\ EN PENSIONES MÍNIMAS EN EL INP EN 2004}

Nuestra estimación del gasto fiscal es el producto del número de beneficiarios por el monto medio del subsidio por beneficiario:

Gasto fiscal $(\mathrm{PM})=\mathrm{N}^{\circ}$ beneficiarios $(\mathrm{PM}) \cdot E[$ Subsidio $]$

\section{A. Número de beneficiarios}

Se utilizan los datos provistos por el INP, Departamento Estadísticas, a diciembre de 2004. Ellos se reportan en el Cuadro № 1 , tercera columna, del texto principal. En diciembre de 2004 hubo 139.223 viudas o madres y 355.267 causantes directos (vejez más invalidez).

\section{B. Subsidio medio por beneficiario}

\section{Aspectos conceptuales}

El monto del subsidio medio en el año 2004 depende de la distribución de valores de las pensiones iniciales de fórmula, reajustadas, y del nivel que alcanzó la pensión mínima en diciembre de 2004. La proporción media de subsidio respecto a la pensión mínima es:

$$
\frac{E[\text { Subsidio }]}{P M} \equiv \frac{1}{P M} \int_{0}^{P M}(P M-x) \cdot f(x) d x,
$$

donde $\mathrm{f}(\mathrm{x})$ es la densidad de las pensiones fórmula.

La pensión fórmula es una fracción $\beta$ del salario base. A su vez, los salarios base son el promedio de los últimos tres o cinco años de salarios imponibles anteriores a la concesión de una pensión. La densidad de los salarios imponibles $\mathrm{g}(\mathrm{w})$ entrega la densidad de los salarios base. Al escalar por $\beta$ se obtiene la densidad $\mathrm{f}(\mathrm{x})$ de las pensiones fórmula.

La densidad lognormal es una forma funcional que recoge de manera parsimoniosa el atributo de asimetría de la densidad de salarios, y entrega una densidad sin discontinuidades artificiales. Es decir, suponemos que los salarios tienen densidad: 
$\mathrm{g}(\mathrm{w}) \equiv \frac{e^{-\frac{1}{2} \cdot\left[\frac{(\ln (w / m)}{\theta}\right]^{2}}}{w \cdot \theta \cdot \sqrt{2 \pi}}$ para $w \geq 0$, donde $\mathrm{m}$ y $\theta$ son parámetros positivos.

La razón media/mediana y la varianza de la lognormal son:

media $/$ mediana $\equiv \mu / M=e^{\theta^{2} / 2} ;$ mediana $=m ;$ varianza $=m^{2} \cdot e^{\theta^{2}} \cdot\left(e^{\theta^{2}}-1\right)$

La primera de estas fórmulas permite deducir el parámetro $\theta$ : $\theta^{2}=2$. ln $(\mu / M)$. También expresamos el monto de la pensión mínima como una proporción " $\alpha$ ” de la mediana de los salarios base, es decir, hacemos PM = $\alpha \cdot$ M. Y lo más importante, transformamos la densidad de los salarios base en la densidad de las pensiones fórmula ${ }^{1}$. Se obtiene:

$$
\frac{E[\text { Subsidio }]}{P M} \equiv \int_{0}^{\alpha} \frac{(\alpha-z)}{\alpha} \cdot \frac{e^{\frac{-1}{4} \cdot \frac{\left[(\ln z / \beta]^{2}\right.}{\ln (\mu / \mathrm{M})}}}{z \cdot \sqrt{4 \pi \ln (\mu / M)}} d z
$$

Esta integral será evaluada numéricamente con MAPLE para los valores de $\alpha, \beta$ y ( $\mu / \mathrm{M})$ que estimaremos en las subsecciones siguientes de este apéndice.

\section{Estimación de $\mu / M$}

El parámetro $\mu / \mathrm{M}$ fue estimado a partir de datos de la distribución de salarios imponibles reportados en 2004 al sistema de capitalización individual. Para estimar el parámetro $\mu / \mathrm{M}$ se usó la distribución acumulativa de la lognormal:

$$
F(w)=\Phi\left(\frac{\ln (w / m)}{\theta}\right) \Leftrightarrow \Phi^{-1}(F(w))=\ln (w / m) / \theta,
$$

donde $\Phi$ es la distribución acumulativa normal estándar. El sistema de capitalización individual publica datos precisos sobre la distribución acumulativa de los salarios imponibles. La Superintendencia de AFP reporta los siguientes seis valores para la distribución acumulativa F de salarios imponibles en diciembre de 2004, a partir de tres millones de datos individuales:

\footnotetext{
${ }^{1}$ Dado $\mathrm{x}=\beta \cdot \mathrm{w}$, esta transformación es $\mathrm{f}(\mathrm{x})=\mathrm{g}(\mathrm{x} / \beta) / \beta$.
} 


\begin{tabular}{lrrrrrr}
\hline $\mathrm{w}($ Salario $)$ & $\$ 100.000$ & $\$ 150.000$ & $\$ 200.000$ & $\$ 250.000$ & $\$ 300.000$ & $\$ 350.000$ \\
$\mathrm{~F}(\mathrm{w})$ & 0,0892 & 0,2759 & 0,4329 & 0,5416 & 0,6207 & 0,6779 \\
$\mathrm{z}=\Phi^{-1}(\mathrm{~F}(\mathrm{w}))$ & $-1,345$ & $-0,596$ & $-0,170$ & 0,105 & 0,308 & 0,464 \\
\hline
\end{tabular}

Fuentes: Boletín Estadístico No 183 de la SAFP (Superintendencia de AFP), p.70; tabla normal.

Esta tabla reporta en su última fila el valor z correspondiente a $\Phi^{-1}(\mathrm{~F}(\mathrm{w}))$. Utilizando la ecuación $\theta=\ln (\mathrm{w} / \mathrm{m}) / \mathrm{z}$ para cada par de valores contiguos de (w) se elimina m y se despeja el parámetro $\theta .^{2}$ El valor promedio obtenido para los distintos pares entrega la media muestral de $\theta$, que es $\mathrm{m}(\theta)=0$,783. La desviación estándar muestral de los valores de $\theta$ es $\mathrm{s}(\theta)=$ 0,178 . Esta muestra tiene $N=5$ observaciones. Según tablas, la distribución t de Student de 4 grados de libertad tiene un valor crítico de 2,1318 para un intervalo de confianza de $90 \%$ con $5 \%$ en cada lado. Luego, el intervalo de confianza al 90\% para el parámetro $\theta$ es $\{\mathrm{m}(\theta)-2,318 \cdot \mathrm{s}(\theta) / \sqrt{5} ; \mathrm{m}(\theta)+$ $2,1318 \cdot \mathrm{s}(\theta) / \sqrt{5}\}$, es decir $\{0,598 ; 0,968\}$.

Estos valores de $\theta$ permiten estimar el cociente entre la media y la mediana. A partir de la fórmula de la razón $\mu / \mathrm{M}$ en función de $\theta$, podemos estimar el rango que recorre $(\mu / \mathrm{M})$. Por un extremo está el valor de $\mu / \mathrm{M}$ que corresponde a $\theta=0,598$ que es 1,20; y por el otro extremo está el valor de $\mu / \mathrm{M}$ que corresponde a 0,968 que es 1,60 . Su valor medio es $\mathrm{E}(\mu / \mathrm{M})=1,36$. Así, nuestra estimación para el parámetro $(\mu / \mathrm{M})$ va desde 1,20 a 1,60, con media en 1,36 .

\section{Estimación de $\alpha$}

Por definición, $\alpha=$ PM/salario base mediano. Pero a su vez el salario base mediano es igual a (salario base medio) $/(\mu / \mathrm{M})$. Como este cociente es conocido, obtenemos $\alpha$ a partir de:

$$
\alpha=(\mu / \mathrm{M}) \cdot(\mathrm{PM} / \text { salario base medio }) \text {. }
$$

El salario base medio en el SSS es el promedio de los salarios imponibles en los últimos cinco años calendario antes de concederse la pensión. En otras cajas era diferente, pero el grueso de los beneficiarios de subsidio de pensión mínima es afiliado del SSS, así que sólo se utilizará la fórmula del SSS. Estimaremos $\alpha$ por separado para causantes y viudas.

\footnotetext{
${ }^{2}$ Cada observación de $\theta$ es $\ln \left(\mathrm{x}_{1} / \mathrm{x}_{2}\right) /\left(\mathrm{z}_{1}-\mathrm{z}_{2}\right)$.
} 


\section{$\alpha$ para causantes}

La esperanza de vida al cumplir los requisitos para la pensión mínima de vejez es 16,52 años para hombres (de 65) (INE, 2002). Esto implica que el pensionado hombre promedio por vejez de diciembre de 2004 inició su pensión en el año 1988. Para el cálculo de su pensión inicial, la fórmula considera el promedio de los salarios imponibles durante los tres o cinco años anteriores, según cuál sea la caja. En el Seguro Social, caja a que pertenece la mayoría de los beneficiarios de pensión mínima, el promedio se toma sobre 5 años, y sólo se actualizan por IPC (hasta la fecha de concesión, 1988) los salarios recibidos en los dos años más lejanos. Es decir, los salarios de 1987 y 1986 nunca son actualizados a 1988.

Para esta generación de hombres el salario medio que rigió en esos años fue:

\begin{tabular}{|c|c|c|c|c|c|}
\hline Año & $\begin{array}{c}\text { Índice general de } \\
\text { remuneraciones } \\
\text { (nominal) }\end{array}$ & $\begin{array}{l}\text { Índice costo } \\
\text { mano de obra } \\
\text { empalmado }\end{array}$ & $\begin{array}{c}\text { IPC del año } \\
\text { (base diciembre } \\
\text { 1998) }\end{array}$ & $\begin{array}{c}\text { Costo M. de O. } \\
\text { actualizado por IPC } \\
\text { hasta dic. } 2004\end{array}$ & $\begin{array}{c}\text { Salario } \\
\text { equivalente en } \\
\text { diciembre de } 2004\end{array}$ \\
\hline
\end{tabular}

(a)

(b)

(c)

(d)

(e)

$\begin{array}{llllll}1984 & 129,22 & 16,787 & 13,49 & 145,40 & \$ 207.013 \\ 1985 & 160,15 & 20,805 & 17,63 & 133,11 & \$ 189.515 \\ 1986 & 197,03 & 25,596 & 28,96^{*} & 103,27 & \$ 147.031 \\ 1987 & 233,92 & 30,388 & 28,96^{*} & 122,60 & \$ 174.552 \\ 1988 & 291,58 & 37,879 & 28,96 & 152,82 & \$ 217.578\end{array}$

Notas: (a) Este índice tiene base 100 en diciembre de 1982. Se tomó el valor del índice en junio de cada año. Fuente: Banco Central (2001) pp. 493-494. (b) El "Índice General de Costo de la Mano de Obra por Hora”, con base abril de 1993 = 100, sustituyó en ese mes al antiguo Índice General de Remuneraciones, que llegó al valor 769,77 en ese mes y luego fue discontinuado. Luego, el factor de empalme es el inverso de 7,6977. (c) En esta columna el índice de precios atribuido a 1986 y 1987 (marcados con *) es el IPC de 1988, con el fin de reflejar el hecho de que, según la fórmula, esos salarios no se reajustan por inflación. El IPC base diciembre 1998 se obtiene de www.bcentral.cl (d) Como el IPC para diciembre de 2004 fue 116,84, en base diciembre de 1998, el índice de remuneraciones nominales en 2004 se obtiene con el factor de conversión (116,84/IPC año t base 98). (e) El "Indice General de Costo de la Mano de Obra por Hora", con base abril de 1993 = 100, tomó el valor 233,51 en diciembre de 2004. En ese mes el promedio del salario imponible a las AFP fue \$ 332.460 (ver Boletín Estadístico No 183 Superintendencia de AFP, p. 59). Se estima el salario de los años 1985-88 en moneda de diciembre de 2004 como \$332.460 x (columna (d)/233,51). 
Tomando el promedio de estos cinco años, el salario base para los causantes fue \$ 187.138 en pesos de diciembre de 2004. Como referencia, es útil mencionar que el ingreso imponible medio cotizado en diciembre de 2004 fue \$ 341.992. En el salario base estimado hemos realizado una aproximación, porque según la fórmula del SSS, el salario imponible de los dos años más lejanos se reajusta por el "salario medio de subsidios", indicador respecto del cual no tenemos datos. Se trata del salario medio de los cotizantes. Si bien en principio podría crecer más rápido que el IPC por efecto de la productividad, sufre también de efectos de composición, que pueden hacer que el promedio varíe en forma negativa aunque todos los individuos estén aumentando su remuneración real. Para simplificar, hemos reajustado solamente por la variación del IPC.

Ahora aplicamos la fórmula $\alpha=(\mu / \mathrm{M}) \cdot(\mathrm{PM} /$ salario base medio $)$. Usaremos nuestra estimación para el rango de valores del cociente $(\mu / \mathrm{M})$, que va desde 1,20 a 1,60. Por otro lado, sabemos que la pensión mínima representativa de causantes de diversas edades $(<70,70-74,75 \mathrm{y}+)$ en diciembre de 2004 fue $\$ 82.311^{3}$. De ambos resulta que el valor de $\alpha$ para los causantes es 0,528 y 0,704 para los valores inferior y superior del cociente $(\mu / \mathrm{M})$, respectivamente. Para el valor medio del cociente $\mu / \mathrm{M}$, que es 1,36 , resulta $\alpha=0,598$.

\section{$\alpha$ para viudas}

La esperanza de vida cuando una viuda cumple el requisito para la pensión mínima de vejez, es decir 60 años, es 23,73 años (INE, 2002). Suponiendo que la viuda es en promedio 3 años menor que su causante, se deduce que el causante de la pensionada por viudez de 2004 inició su pensión en 1977 (= 2004 - 23,73 - 3). El promedio de los salarios imponibles del causante se toma sobre los cinco años que terminan en 1977 . No se actualizan por IPC (hasta la fecha de concesión, 1977) los salarios recibidos en 1975 y 1976, pero sí los de 1973 y 1974. La enorme inflación legada por la Unidad Popular, combinada con la ausencia de ajustes razonables por inflación legada por los gobiernos de 1924-1977, erosionó dramáticamente la pensión fórmula.

Los salarios de los causantes en 1973-1977, cuando fueron concedidas las pensiones pagadas en 2004, están en la primera columna de la siguiente tabla:

${ }^{3} \mathrm{El}$ monto de la pensión mínima a esa fecha fue \$ 77.077 para los menores de 70 años, \$ 84.277 para los de entre 70 y 75, y \$ 86.079 para los mayores de 75 años. Considerando que la proporción de cada grupo de edad dentro de los pensionados fue 38,03\%, 19,14\% y 42,83\% respectivamente (Riesco 2005, p. 18), estimamos que la pensión mínima representativa para ese año fue \$ 82.311 al mes. 


\begin{tabular}{|c|c|c|c|c|}
\hline Año & $\begin{array}{c}\text { Salario } \\
\text { nominal medio } \\
\text { (a) }\end{array}$ & $\begin{array}{c}\text { IPC anual } \\
\text { (base diciembre 1978) } \\
\text { (b) }\end{array}$ & \multicolumn{2}{|c|}{$\begin{array}{l}\text { Salario equivalente en } \\
\text { diciembre de } 2004 \\
\text { (c) }\end{array}$} \\
\hline 1973 & \$ 11,072 & 0,3715 & $\$$ & 83.586 \\
\hline 1974 & $\$ 76,368$ & 2,2466 & $\$$ & 95.334 \\
\hline 1975 & $\$ \quad 328$ & $63,859 *$ & $\$$ & 14.405 \\
\hline 1976 & \$ 1.229 & $63,859 *$ & $\$$ & 53.975 \\
\hline 1977 & \$ 3.014 & 63,859 & $\$$ & 132.369 \\
\hline
\end{tabular}

Notas: (a) Se usó la Remuneración Media Nominal para el sector Manufacturas, promedio de obreros y empleados, obtenido de Banco Central (1989), p. 213. (b) Aquí también se usa el IPC del año en que se concedió la pensión, con el fin de reconocer que la fórmula no ajustaba el salario pasado por inflación. La fuente es Banco Central (1989), p. 169. (c) El IPC medio para 1982 fue 212,19, base diciembre de 1978. Según www.bcentral.cl el IPC medio de 1982 fue 8,84, base diciembre de 1998, y el IPC para diciembre de 2004 fue 116,84, en base diciembre de 1998. Luego, el factor de conversión de los salarios es (212,19/IPC base 78 año t) x $(116,84 / 8,84)$.

La última columna permite determinar, con un simple promedio, que, el salario base para la pensión fórmula de los causantes fue \$ 75.934 en pesos de diciembre de 2004. Por otro lado, la fórmula indica que la viuda recibe el $60 \%$ de la pensión del causante. Por eso, el salario base promedio para las viudas es $0,60 \times \$ 75.934=\$ 45.560$.

De nuevo aplicamos la fórmula $\alpha=(\mu / \mathrm{M}) \bullet(\mathrm{PM} /$ salario base medio $)$. Usamos nuestra estimación para el rango de valores del cociente $(\mu / \mathrm{M})$, que va desde 1,20 a 1,60. La pensión mínima para la viuda representativa ${ }^{4}$ en diciembre de 2004 fue el $68,7 \%$ de $\$ 82.311$, es decir \$ 56.548. De aquí resulta que el valor de $\alpha$ para las viudas es 1,489 y 1,986 para los valores inferior y superior del cociente $(\mu / \mathrm{M})$, respectivamente. Para el valor medio del cociente $\mu / \mathrm{M}$, que es 1,36 , resulta que $\alpha=1,688$.

${ }^{4} \mathrm{El}$ 68,7\% es un promedio que considera las bonificaciones especiales concedidas a las viudas por las leyes 19.403, 19.539 y 19.953. El cociente entre la pensión mínima de la viuda sin hijos y una pensión mínima de vejez es 0,6489 para las viudas entre 60 y 70 años de edad, 0,7405 entre 70 y 75 años, y 0,6940 para las mayores de 75. Ponderando según el número de viudas en cada grupo de edad en diciembre de 2004 (lo cual incluye suponer que 2/3 de las mayores de 70 son también mayores de 75), se obtiene el promedio indicado de 0,687. También se supone que la tasa de reemplazo de la viuda sin hijos es representativa de los siguientes casos: viuda sin hijos $60 \%$, viuda más un hijo dependiente $65 \%$, viuda más dos hijos dependientes $80 \%$, madre de filiación no matrimonial si la viuda no tiene hijos $36 \%$, y madre de filiación no matrimonial si la viuda tiene uno o más hijos 0,30. 


\section{Tasa de reemplazo $\beta$}

El grueso de los beneficiarios del subsidio de pensión mínima pertenece al Servicio de Seguro Social, así que utilizaremos la fórmula de beneficio de esa caja. Para los hombres, una vez que completan 800 semanas de cotización, la Pensión Fórmula $=\left[0,50+0,01 \cdot\right.$ Parte Entera $\left[\left(\mathrm{N}^{\circ}\right.\right.$ Semanas de Servicio/50) - 10] • (1/1,2020) • (Promedio de salario mensual en 5 años anteriores al inicio de la pensión), siempre que la densidad de cotización de toda la afiliación haya superado 50\%. La densidad promedio de cotizaciones contada desde la primera cotización, reportada en la encuesta HLSS02, es 67\% (Cox, 2006), así que según este supuesto la gran mayoría cumple el requisito de $50 \%$.

Por otro lado, se nos ha informado en el INP que para muchos pensionados por vejez $\beta$ es cero, debido a que no cotizaron en ninguno de los cinco años calendario anteriores a la emisión de su pensión (que se emite cuando cumple 65H/60M), posiblemente por renuncia o despido. Por ignorancia e iliquidez tampoco continuaron cotizando desde un empleo ficticio. Suponiendo que un $25 \%$ de los causantes está en esta situación $(\beta=0)$ y que el resto tuvo una densidad media de $67 \%$ sobre una carrera de 40 años, es decir 1.394 semanas de servicio, resulta una tasa media de reemplazo de $0,25 \cdot 0+0,75 \cdot[0,50+0,01 x$ Parte Entera $(1394 / 50)-10] \cdot(1 / 1,2020)=41,8 \%$ $(\beta=0,418)$.

Respecto a los causantes de las viudas, la fórmula del Seguro Social entrega nuevamente una tasa de reemplazo media de $41,8 \%$ para el mismo supuesto de densidad de cotización.

\section{Subsidio medio en \$/beneficiario}

Ahora evaluamos con MAPLE la expresión del subsidio esperado asociada a la distribución lognormal, utilizando los parámetros recién identificados $(\mu / \mathrm{M}, \alpha, \beta)$, para el intervalo de $90 \%$ de confianza y para la estimación punto. Los resultados son:

\begin{tabular}{ll|rrr}
\hline $\begin{array}{l}\text { E(subsidio)/PM } \\
\text { para } \beta=0,418(\%)\end{array}$ & & \multicolumn{3}{|c}{ Cociente $\mu / \mathrm{M}$} \\
\cline { 3 - 5 } & & 1,20 & 1,36 & 1,60 \\
\hline $\begin{array}{l}\text { Valores de } \alpha \\
(\alpha=\text { PM/mediana) }\end{array}$ & 0,528 & $25,6 \%$ & $*$ & $*$ \\
& 0,598 & $*$ & $32,0 \%$ & $*$ \\
& 0,699 & $*$ & $*$ & $38,4 \%$ \\
& 1,489 & $66,8 \%$ & $*$ & $*$ \\
& 1,688 & $*$ & $67,9 \%$ & $*$ \\
& 1,989 & $*$ & $*$ & $69,8 \%$ \\
\hline
\end{tabular}

Nota: * = no aplica. Agradezco a Gonzalo Valdés E. por su eficiente programación. 
Se observa que la proporción de subsidio es mayor para las pensiones de viudas que para las de causantes. Sin embargo, los montos de las pensiones mínimas difieren en la dirección inversa (es \$ 82.311 para causantes y \$ 56.548 para viudas). La siguiente tabla muestra el monto del subsidio promedio por beneficiario, medido en pesos al mes.

\begin{tabular}{|c|c|c|c|c|c|}
\hline \multirow{2}{*}{\multicolumn{2}{|c|}{$\begin{array}{l}\text { E(subsidio) } \\
\text { (\$/mes) }\end{array}$}} & & \multicolumn{3}{|c|}{ Cociente $\mu / \mathrm{M}$} \\
\hline & & & 1,20 & 1,36 & 1,60 \\
\hline \multirow[t]{2}{*}{$\begin{array}{l}\text { Valores de } \alpha \\
(\alpha=\text { PM/mediana) }\end{array}$} & Causantes & $\begin{array}{l}0,528 \\
0,598 \\
0,699\end{array}$ & $\begin{array}{r}\$ 21.072 \\
* \\
*\end{array}$ & $\begin{array}{r}* \\
\$ 26.340 \\
*\end{array}$ & $\begin{array}{r}* \\
* \\
\$ 31.607\end{array}$ \\
\hline & Viudas & $\begin{array}{l}1,489 \\
1,688 \\
1,989\end{array}$ & $\begin{array}{r}\text { \$ } 37.774 \\
* \\
*\end{array}$ & $\begin{array}{r}* \\
\$ 38.396 \\
*\end{array}$ & $\begin{array}{r}* \\
* \\
\$ 39.471\end{array}$ \\
\hline
\end{tabular}

Nota: $*=$ no aplica.

Vemos que la estimación para las viudas es más precisa que para los causantes, para un mismo nivel de confianza de $90 \%$.

\section{Gasto fiscal en pensión mínima del año 2004}

Ahora combinamos los datos respecto al número de beneficiarios con los resultados respecto del monto de subsidio por beneficiario. El resultado es el siguiente:

\begin{tabular}{lrrrr}
\hline Grupo & $\begin{array}{c}\text { Escenario } \\
\text { de gasto }\end{array}$ & $\begin{array}{c}\text { Subsidio por } \\
\text { beneficiario } \\
(\$ / \text { mes })\end{array}$ & $\begin{array}{c}\mathrm{N}^{\circ} \text { de } \\
\text { beneficiarios }\end{array}$ & $\begin{array}{c}\text { Gasto fiscal } \\
\text { anual } \\
\text { (mill. } \$)\end{array}$ \\
\hline Causantes & Bajo & $\$ 21.072$ & & $\$ 89.834$ \\
& Medio & $\$ 26.340$ & 355.267 & $\$ 112.293$ \\
Alto & $\$ 31.607$ & & $\$ 134.747$ \\
Viudas & Bajo & $\$ 37.774$ & & $\$ 63.112$ \\
& Medio & $\$ 38.396$ & 139.233 & $\$ 64.152$ \\
& Alto & $\$ 39.471$ & & $\$ 65.948$ \\
\hline
\end{tabular}


Sumando causantes y viudas, concluimos que, con un $90 \%$ de confianza, el gasto fiscal en subsidio de pensión mínima del sistema antiguo, durante el año 2004, estuvo entre \$ 152.946 y \$ 200.695 millones de pesos. En el escenario central el gasto fiscal en subsidios de pensión mínima habría sido \$ 176.445 millones, que equivale a 0,31\% del PIB de $2004^{5}$. El intervalo de confianza va de $0,27 \%$ del PIB a $0,35 \%$ del PIB.

\section{ANEXO 2}

\section{ESTIMACIÓN DEL GASTO FISCAL EN PENSIONES MÍNIMAS QUE EL INP HABRÍA TENIDO EN 2004 SI HUBIERA REGIDO UN AUMENTO DE 10\% EN LAS PENSIONES MÍNIMAS}

También esta estimación del gasto fiscal es el producto del número de beneficiarios por el monto medio del subsidio por beneficiario. Ambos conceptos aumentan al elevarse el monto de la pensión mínima en 10\% real, por sobre la inflación. Los dos términos de la expresión que determina el gasto fiscal dependen del nivel de la pensión mínima (PM):

$$
\begin{aligned}
& \text { Gasto Fiscal }(\mathrm{PM})=\mathrm{N}^{\circ} \text { Beneficiarios }(\mathrm{PM}) \cdot E[\text { Subsidio }] \text {; luego, } \\
& \Delta \% \text { Gasto Fiscal }=\left(1+\Delta \% \mathrm{~N}^{\mathrm{o}} \text { Beneficiarios }\right) \cdot(1+\Delta \% E[\text { Subsidio }])-1
\end{aligned}
$$

\section{A. Tasa de aumento del subsidio medio}

El subsidio medio es el producto de la proporción media de subsidio por el monto de la pensión mínima:

$$
\begin{gathered}
E[\text { Subsidio }]=\left(\frac{E[\text { Subsidio }]}{P M}\right) \cdot \mathrm{PM}, \mathrm{y} \text { por tanto } \\
\Delta \% E[\text { Subsidio }]=(1+\Delta \% E[\text { Subsidio }]) \cdot(1+\Delta \% P M)-1 .
\end{gathered}
$$

La tasa de aumento en la proporción media de subsidio se define como:

$$
\Delta \% \text { Tasa Media Subsidio } \equiv \frac{E\left[\text { Subsidio }\left(1,1 \bullet P M_{0}\right) / 1,1 \bullet P M_{0}\right]-E\left[\text { Subsidio }\left(P M_{0}\right) / P M_{0}\right]}{E\left[\operatorname{Subsidio}\left(P M_{0}\right) / P M_{0}\right]}
$$

${ }^{5}$ El PIB nominal de 2004 fue de \$ 57.357 millones de pesos. 
Ahora expresamos el monto de la pensión mínima como una proporción " $\alpha$ ” de la mediana de los salarios base, es decir hacemos $\mathrm{PM}_{0}=\alpha_{0} \cdot \mathrm{M}$. Usando la densidad lognormal ya determinada, y aplicando algunos cambios de variable, se obtiene:

E[Subsidio $\left.\left(1,1 \cdot P M_{0}\right) / 1,1 \cdot P M_{0}\right]=\int_{0}^{1,1 \cdot \alpha_{0}} \frac{\left(1,1 \cdot \alpha_{0}-z\right)}{1,1 \cdot \alpha_{0}} \cdot \frac{e^{\frac{-1}{4} \cdot \frac{\left[(\ln (z / \beta)]^{2}\right.}{\ln (\mu / M)}}}{z \cdot \sqrt{4 \pi \ln (\mu / M)}} d z, y$

$E\left[\operatorname{Subsidio}\left(P M_{0}\right) / P M_{0}\right]=\int_{0}^{\alpha_{0}} \frac{\left(\alpha_{0}-\mathrm{z}\right)}{\alpha_{0}} \cdot \frac{e^{\frac{-1}{4} \cdot \frac{\left[(\ln (z / \beta)]^{2}\right.}{\ln (\mu / M)}}}{z \cdot \sqrt{4 \pi \ln (\mu / M)}} d z$

Usamos MAPLE para calcular numéricamente la tasa de aumento en la proporción media de subsidio. Recordamos que $\beta=0,418$ y que $\alpha_{0}$ toma valores en un intervalo de $90 \%$ de confianza, que son diferentes para causantes y viudas. El resultado es:

\begin{tabular}{ll|rrr}
\hline \multirow{2}{*}{$\begin{array}{l}\Delta \% \mathrm{E}\{\text { Subsidio/PM }\} \\
\text { para } \beta=0,418(\%)\end{array}$} & & \multicolumn{3}{|c}{ Cociente $\mu / \mathrm{M}$} \\
\cline { 3 - 5 } & & & \multicolumn{3}{c}{1,36} & 1,60 \\
\hline \multirow{2}{*}{$\begin{array}{l}\text { Valores de } \alpha \\
(\alpha=\mathrm{PM} / \text { mediana) })\end{array}$} & 0,528 & $14,9 \%$ & $*$ & $*$ \\
& 0,598 & $*$ & $10,6 \%$ & $*$ \\
& 0,699 & $*$ & $*$ & $7,8 \%$ \\
& 1,489 & $4,3 \%$ & $*$ & $*$ \\
& 1,688 & $*$ & $3,9 \%$ & $*$ \\
& 1,989 & $*$ & $*$ & $3,3 \%$ \\
\hline
\end{tabular}

Nota: * = no aplica.

Se ve que la tasa de aumento de la proporción media de subsidio para viudas beneficiarias es menor que la tasa análoga para causantes. La explicación intuitiva es que la proporción de subsidio que recibían las viudas en la situación inicial era mucho mayor que la proporción inicial de subsidio para los causantes.

Como la tasa de aumento de la pensión mínima fue $10 \%$, $\Delta \% \mathrm{E}[$ Subsidio $]=(1+\Delta \% \mathrm{E}[$ Subsidio $]) \cdot 1,10-1, \mathrm{y}$ obtenemos la tasa de aumento en el subsidio promedio: 


\begin{tabular}{|c|c|c|c|c|}
\hline \multirow{2}{*}{$\begin{array}{l}\Delta \% \text { E }\{\text { Subsidio }\} \\
\text { para } \beta=0,418 \text { (\%) }\end{array}$} & & \multicolumn{3}{|c|}{ Cociente $\mu / \mathrm{M}$} \\
\hline & & 1,20 & 1,36 & 1,60 \\
\hline \multirow[t]{6}{*}{$\begin{array}{l}\text { Valores de } \alpha \\
\text { ( } \alpha=\text { PM/mediana) }\end{array}$} & 0,528 & $26,4 \%$ & * & * \\
\hline & 0,598 & $*$ & $21,7 \%$ & * \\
\hline & 0,699 & * & $*$ & $18,6 \%$ \\
\hline & 1,489 & $14,7 \%$ & * & * \\
\hline & 1,688 & * & $14,3 \%$ & * \\
\hline & 1,989 & * & * & $13,6 \%$ \\
\hline
\end{tabular}

Nota: $*=$ no aplica.

El motivo por el cual esta tasa de incremento es mayor que $10 \%$ se ve en el siguiente ejemplo: aquellos pensionados cuya pensión autofinanciada es \$ 79.000 reciben un subsidio de \$ 1.000 en una situación inicial donde la pensión mínima es \$ 80.000. Al subir la pensión mínima en 10\%, ésta llega a \$ 88.000 y el subsidio de esta persona sube a \$ 9.000. La tasa de aumento del subsidio es (\$ 8.000/\$ 1.000)x100 = 800\%. Es evidente que el promedio ponderado de las tasas de aumento siempre debe ser superior a $10 \%$.

\section{B. Tasa de aumento en el número de beneficiarios}

Si $\mathrm{f}(\mathrm{x})$ es la densidad de pensiones fórmula, entonces la tasa de aumento en el número es:

$$
\Delta \% N \equiv \frac{N\left(1,1 \cdot P M_{0}\right)-N\left(P M_{0}\right)}{N\left(P M_{0}\right)}=\int_{P M_{0}}^{1,1 P M_{0}} f(x) d x / \int_{0}^{P M_{0}} f(x) d x
$$

Usando la densidad lognormal ya determinada, y haciendo cambios de variables análogos a los del Anexo 1, encontramos que:

$$
\Delta \% N=\int_{\alpha_{0}}^{1,1 \alpha_{0}} z^{-1} \cdot e^{\frac{-1}{4} \cdot \frac{[\ln (z / \beta)]^{2}}{\ln (\mu / \mathrm{M})}} d z / \int_{0}^{\alpha_{0}} z^{-1} \cdot e^{\frac{-1}{4} \cdot \frac{[\ln (z / \beta)]^{2}}{\ln (\mu / \mathrm{M})}} d z
$$

De nuevo usamos MAPLE para calcular numéricamente esta tasa, recordando que $\beta=0,418$ y que $\alpha_{0}$ toma valores en un intervalo de $90 \%$ de confianza, que son diferentes para causantes y viudas. El resultado es: 


\begin{tabular}{|c|c|c|c|c|}
\hline \multirow{2}{*}{$\begin{array}{c}\Delta \% \mathrm{~N} \\
\text { para } \beta=0,418(\%)\end{array}$} & & \multicolumn{3}{|c|}{ Cociente $\mu / \mathrm{M}$} \\
\hline & & 1,20 & 1,36 & 1,60 \\
\hline \multirow[t]{6}{*}{$\begin{array}{l}\text { Valores de } \alpha \\
\text { ( } \alpha=\mathrm{PM} / \text { mediana })\end{array}$} & 0,528 & $8,68 \%$ & $*$ & $*$ \\
\hline & 0,598 & $*$ & $6,27 \%$ & * \\
\hline & 0,699 & $*$ & $*$ & $4,72 \%$ \\
\hline & 1,489 & $0,6 \%$ & $*$ & * \\
\hline & 1,688 & $*$ & $0,9 \%$ & * \\
\hline & 1,989 & $*$ & $*$ & $1,0 \%$ \\
\hline
\end{tabular}

Nota: $*=$ no aplica.

Las tasas de incremento en el número difieren marcadamente entre causantes y viudas. La explicación es que como la proporción de viudas que recibía subsidio en la situación inicial era mucho mayor que la de causantes, el espacio para incrementos es más reducido para viudas.

El siguiente cuadro muestra que el aumento absoluto en el número de beneficiarios es mucho mayor para los causantes. Ello también se debe a que en la situación inicial había mucho más causantes (355.267) que viudas (139.233) recibiendo subsidios:

\begin{tabular}{ll|rrr}
\hline \multirow{2}{*}{$\begin{array}{c}\Delta \mathrm{N} \\
\text { para } \beta=0,418(\%)\end{array}$} & & \multicolumn{3}{|c}{ Cociente $\mu / \mathrm{M}$} \\
\cline { 3 - 5 } & & 1,20 & 1,36 & 1,60 \\
\hline \multirow{2}{*}{$\begin{array}{l}\text { Valores de } \alpha \\
(\alpha=\text { PM/mediana) }\end{array}$} & 0,528 & 30.837 & $*$ & $*$ \\
& 0,598 & $*$ & 22.275 & $*$ \\
& 0,699 & 835 & $*$ & 16.769 \\
& 1,489 & $*$ & 1.253 & $*$ \\
& 1,688 & $*$ & $*$ & 1.392 \\
& 1,989 & & & $*$ \\
\hline
\end{tabular}

Nota: $*=$ no aplica.

\section{Aumento en el gasto fiscal en subsidios de pensión mínima}

Ahora combinamos la tasa de aumento en el monto medio de subsidios con la tasa de aumento en el número de beneficiarios. Se obtiene que: 


\begin{tabular}{ll|rrr}
\hline $\begin{array}{l}\Delta \% \text { Gasto fiscal } \\
\text { para } \beta=0,418 \text { (\%) }\end{array}$ & & \multicolumn{3}{|c}{ Cociente $\mu / \mathrm{M}$} \\
\cline { 3 - 5 } & & & 1,36 & 1,60 \\
\hline \multirow{2}{*}{$\begin{array}{l}\text { Valores de } \alpha \\
(\alpha=\text { PM/mediana) }\end{array}$} & 0,528 & $37,4 \%$ & $*$ & $*$ \\
& 0,598 & $*$ & $29,3 \%$ & $*$ \\
& 0,699 & $*$ & $*$ & $24,2 \%$ \\
& 1,489 & $15,4 \%$ & $*$ & $*$ \\
& 1,688 & $*$ & $15,3 \%$ & $*$ \\
& 1,989 & $*$ & $*$ & $14,7 \%$ \\
\hline
\end{tabular}

Nota: $*=$ no aplica.

Este resultado confirma la intuición de Bennett y Schmidt-Hebbel (2001), en cuanto a que el costo fiscal del aumento en pensiones mínimas sería marcadamente no lineal. El incremento de gasto es relativamente mayor para los grupos donde el gasto inicial era menor.

Por último, combinamos este resultado con los datos respecto al gasto fiscal inicial, para determinar el nuevo costo fiscal absoluto. El resultado entrega un intervalo de confianza al $90 \%$ bastante más preciso que los del Anexo 1, y es el siguiente:

\begin{tabular}{llllll}
\hline Grupo & $\begin{array}{c}\text { Escenario } \\
\text { de gasto } \\
\text { inicial }\end{array}$ & $\begin{array}{c}\text { G. fiscal } \\
\text { inicial } \\
\text { (mill. } \\
\text { \$/año) }\end{array}$ & $\begin{array}{c}\text { Aumento de } \\
\text { gasto debido } \\
\text { a alza de } 10 \%\end{array}$ & $\begin{array}{c}\text { Incremento de gasto fiscal } \\
\text { en p. mínima }\end{array}$ & anual debido al alza \\
\cline { 5 - 6 } & & & & & $\begin{array}{c}\text { (mill. \$) } \\
\text { (incr. como } \\
\% \text { del PIB) }\end{array}$ \\
\hline Suma de & Bajo & $\$ 152.946$ & $29,9 \%$ & $\$ 43.317$ & $0,076 \%$ \\
causantes & Medio & $\$ 176.445$ & $25,2 \%$ & $\$ 42.717$ & $0,074 \%$ \\
y viudas & Alto & $\$ 200.695$ & $21,7 \%$ & $\$ 42.303$ & $0,074 \%$ \\
\hline
\end{tabular}

Si se hubiera realizado en 2004, el aumento de $10 \%$ en la pensión mínima habría costado en ese año solamente 0,074\% del PIB en el escenario central.

ANEXO 3

RESERVA PARA RESPALDAR LAS PENSIONES DE LAS FUERZAS ARMADAS Y CARABINEROS

La OCDE recomienda reconocer como pasivos fiscales solamente a aquellos derivados de promesas de pensión que sean parte del paquete remuneratorio ofrecido por el Estado a algunos empleados. La OCDE reconoce los casos donde los empleados del Estado poseen derechos de propiedad exigibles por concepto de remuneración, diferida como pensión. 
La OCDE también intenta que todos los empleadores, sean empresas privadas o gobiernos, contabilicen sus pasivos por pensiones adicionales a las obligatorias para la población en general, con una metodología contable uniforme, con el fin de obligar a todos a respaldar sus promesas de pago en forma similar, es decir con inversiones o reservas financieras cuyo valor sea independiente de la situación económica del empleador. Esta igualdad facilitaría la movilidad laboral entre los sectores público y privado, con consecuencias favorables para la eficiencia y la equidad horizontal.

Como se indicó en el texto, el único pasivo relacionado con pensiones que Nueva Zelanda reporta en su balance es "GSF Pension Liability". Este pasivo se deriva de los derechos de propiedad que poseen los empleados del Estado en Nueva Zelanda por concepto de remuneraciones diferidas en la forma de pensiones.

El monto de pasivo fiscal GSF Pension Liability es la diferencia entre el valor presente esperado de las pensiones comprometidas por ese empleador (el Estado neozelandés) como remuneración diferida con sus propios empleados, y el valor de las inversiones que respaldan dicho pasivo y que administra la caja o institución previsional que paga dichas pensiones. Estas inversiones deben ser valoradas a precios de mercado ${ }^{1}$.

Respecto a la forma en que opera este plan de pensiones para empleados públicos, que fue cerrado a nuevos miembros en 1992, se sugiere ver http://www.gsfa.govt.nz Desde 1998 los nuevos oficiales que ingresan a las fuerzas armadas neozelandezas deben cumplir una permanencia mínima de seis años para tener derecho a beneficios ${ }^{2}$.

En Chile también existe este pasivo, pero sólo con los afiliados de las cajas de previsión de la Defensa Nacional (Capredena) y de la Dirección de Previsión de Carabineros (Dipreca). Las pensiones prometidas por ley a ellos son parte de la remuneración pactada cuando ingresaron a la respectiva institución. Ello se deduce del hecho de que desde fines del siglo XIX la tasa de contribución de esos trabajadores ha sido baja en comparación con los beneficios. Tan baja, que esas cajas nunca han cumplido el requisito actuarial para ser clasificadas como de régimen contributivo. Ese requisito

${ }^{1}$ Ver la nota 14 del balance al 31 de enero de 2006, en p. 37 del informe disponible en www.treasury.govt.nz/financialstatements/month/jan06/cfs7jan06.pdf El pasivo (bruto) del GSF alcanzó a esa fecha a 15.208 millones de dólares neozelandeses, y el valor del fondo de pensiones disponible alcanzó a 3.711 millones, dejando como pasivo neto 11.497 millones de dólares neozelandeses.

${ }^{2}$ Sin embargo, este beneficio es del tipo contribución definida y no de beneficio definido, como en Chile (ver más detalles en www.nzdf.mil.nz/personnel-records/per/ sonnel-branch.htm\#gsf). 
es que el valor presente esperado de las cotizaciones, para un horizonte infinito, sea similar al valor presente esperado de los beneficios.

Según el FMI (2005), el déficit de caja de Capredena y Dipreca sería 1,6\% del PIB en 2020-2030. Sin embargo, el estudio que respalda esta proyección nunca ha sido publicado por el FMI, ni por la Dirección de Presupuestos. Es curioso que se afirme que el monto del déficit flujo (de caja) crezca más rápido que el PIB, siendo que desde 1990 los retiros en las Fuerzas Armadas ocurren a una edad más joven que durante el régimen militar (1973-1990). Por otro lado, el sostenido aumento en la dotación policial y de gendarmes (guardias carcelarios) sugiere que el volumen de remuneraciones diferidas pagadas por intermedio de Dipreca aumentará en el futuro.

En el evento de que esta estimación de déficit flujo fuera correcta, entonces la adopción de la mejor práctica fiscal internacional exigiría al fisco chileno constituir una reserva fiscal importante. Suponiendo que la duración media del pasivo fuera de 30 años (contando desde el paso a retiro hasta la extinción), que la tasa de descuento sea 5\% real, y que el PIB crezca al 3\% real anual, el monto de este pasivo sería de 35\% del $\mathrm{PIB}^{3}$. Esta cifra podría caer significativamente si en el futuro una ley reservara el acceso a este paquete remuneratorio al personal propiamente militar, que es el único cuyo entrenamiento es financiado por el fisco.

\section{BiBLIOGRAFÍA}

Acuña, R. y A. Iglesias (2000): “La Reforma a las Pensiones”. En F. Larraín y R. Vergara (eds.), La Transformación Económica de Chile. Santiago: Centro de Estudios Públicos.

Arellano, J. P. (1985): Políticas Sociales y Desarrollo: Chile 1924-1984. Santiago: CIEPLAN.

Arenas de Mesa, A. (2004): "Política Fiscal y Garantías Explícitas del Sistema de Pensiones en Chile”. XVI Seminario Regional de Política Fiscal, enero 2004, CEPAL, Santiago.

Arenas de Mesa, A. y P. Gana (2005): "Proyecciones del Gasto Previsional en Chile, Bonos de Reconocimiento 2005-2038”. Serie Estudios de Finanzas Públicas $\mathrm{N}^{\circ}$ 6, Dirección de Presupuestos, www.dipres.cl

Arenas de Mesa, A. y J. Guzmán (2003): "Política Fiscal y Protección Social en Chile”. En Revista de la Cepal, 81, pp. 123-141.

Arenas de Mesa, A. y M. Marcel (1999): "Fiscal Effects of Social Security Reform in Chile: The case of the Minimum Pension”. En volumen Segundo Foro Regional APEC sobre Reformas de Pensiones, Viña del Mar, Chile, 26 y 27 de abril.

${ }^{3}$ La fórmula es 1,6 (\% del PIB) • [1- (1+r/1+g)-Duración Media $] /(r-g)$. 
Arenas de Mesa, A. y C. Mesa-Lago (2006): "The Structural Pension Reform in Chile: Effects, Comparisons with other Latin American Reforms, and Lessons”. En Oxford Review of Economic Policy, Vol. 22 No 1, pp. 149-167.

Banco Central (1989): Indicadores Económicos y Sociales 1960-1983. Santiago: Banco Central de Chile.

Banco Central (2001): Indicadores Económicos y Sociales de Chile 1960-2000. Santiago: Banco Central de Chile.

Bennett, H. y K. Schmidt-Hebbel (2001): "Déficit Previsional del Sector Público y Garantía de Pensión Mínima”. Nota Técnica en Economía Chilena, Vol. 4, $N^{\circ}$ 3, Banco Central de Chile, Santiago.

Beyer, H. (1997): “Distribución del Ingreso: Antecedentes para la Discusión”. Estudios Públicos, 60 (primavera).

Beyer, H. (2000): “Educación y Desigualdad de Ingresos: Una Nueva Mirada”. Estudios Públicos, 77 (verano).

Campbell, John y Luis Viceira (2002): Strategic Asset Allocation: Portfolio Choice for Long term Investors. Oxford University Press.

CEPAL (2006): Protección Social de Cara al Futuro: Acceso, Financiamiento y Solidaridad. Febrero, disponible en www.eclac.org

Cheyre, H. (1988): La Previsión Ayer y Hoy. Santiago: Centro de Estudios Públicos.

Chumacero, R. y R. Paredes, (2005): "Characterizing Income Distribution for Poverty and Inequality Analysis”. En Estudios de Economía, Vol. 32, No 1, p. 97, Santiago, Chile.

Cox, Alejandra (2006): "Another Look at Contribution Densities in the Chilean System”. Mimeo, April.

Diamond, P. y S. Valdés (1994): “Social Security Reforms”. Capítulo 6, en Bos-worth, B., R. Dornbusch y R. Labán (eds.), Chilean Economy: Policy Lessons and Challenges. Washington, D. C.: Brookings Institution.

Dirección de Presupuestos (2000): Aspectos Macroeconómicos del Proyecto de Ley de Presupuestos del Sector Público del Año 2001. Octubre, Santiago.

Dirección de Presupuestos (2001): Aspectos Macroeconómicos del Proyecto de Ley de Presupuestos del Sector Público del Año 2002. Septiembre, Santiago.

Dirección de Presupuestos (2002) hasta (2005): Informe de Finanzas Públicas 2003 a 2006, Santiago.

Dirección de Presupuestos (2006a): "Ejecutivo Entrega Diagnóstico del Sistema de Pensiones Chileno al Consejo Asesor Presidencial para la Reforma Previsional”. Comunicado de Prensa en www.dipres.cl

Dirección de Presupuestos (2006b): "Informe Financiero al Congreso $\mathrm{N}^{\circ}$ 09, sobre Proyecto de Ley que Reajusta Pensiones Más Bajas (Mensaje $N^{\circ}$ 25-354)”, de fecha 20 de marzo de 2006, Santiago.

FMI (Fondo Monetario Internacional) (2001): "Manual de Transparencia Fiscal". http://www.imf.org/external/np/fad/trans/manual/index.htm

FMI (2003): "Chile: Report on the Observance of Standars and Codes (ROSC) Fiscal Transparency Module”. En Fiscal Affairs Departament, July 24, Washington, D.C.

FMI (2005): "Addressing the Long-Run Shortfalls of the Chilean Pension System". Cap. I, en Chile: Selected Issues, IMF Country Report $N^{\circ}$ 05/316. Washington D.C.: FMI. 
Gálvez, J. y V. Clarke (varios años): “Contabilidad Financiera para la Dirección de Empresas”. Edición interna Escuela de Administración de la Pontificia Universidad Católica de Chile, Santiago.

Geanokoplos, J., O. Mitchell y S. Zeldes (1998): "Would a Privatized Social Security System Really Have a Higher Rate of Return?” En R. D. Arnold, M. J. Graetz y A. H. Munnell (eds.), Framing the Social Security Debate: Values, Politics and Economics. National Academy of Social Insurance, Brookings Institution Press.

Holzmann, R. (1997): "Pension Reform, Financial Market Development and Economic Growth: Preliminary Evidence from Chile”. IMF Staff Papers 44, $\mathrm{N}^{\circ} 2$ (junio), pp. 149-178.

INE (Instituto Nacional de Estadísticas) (2002): “Tablas Abreviadas de Mortalidad por Sexo, Total País y Regiones 2001-2002”. En www.ine.cl/ine/canales/ chile_estadistico/demografia_y_vitales/estadisticas_vitales/pdf/ tablasmortalidadporsexo2001_02.pdf

Informe Prat (1959): Informe sobre la Reforma de la Seguridad Social Chilena, Volumen IV, Sobre beneficios en el Servicio de Seguro Social. Sección de Trabajadores Manuales. Santiago: Editorial Jurídica de Chile, 1964.

Kotlikoff, L. (2004): Generational Policy. MIT Press.

Kotlikoff, L. y S. Burns, (2004): The Coming Generational Store. MIT Press.

Kotlikoff, L. y C. Hagist (2005): “Who’s Going Broke? Comparing Growth in HealthCare Costs in Ten OECD Countries". NBER WP N 11.833, Cambridge, Massachusetts.

Novoa Fuenzalida, P. (1977): Derecho de la Seguridad Social. Santiago: Editorial Jurídica de Chile.

OCDE (2001): "Buenas Prácticas en Transparencia Presupuestaria”. www.olis.oecd.org/ olis/2000doc.nsf/87fae4004d4fa67ac125685d005300b3c125692700623b74c 1256a4d005c23be?OpenDocument.

Ortúzar, P. (1986): "Proyecciones del Déficit Operacional 1985-2015, Parte I y Parte II”. Santiago: Oficina de Planificación Nacional (Odeplan).

Poder Ejecutivo (2006): "Informe de Diagnóstico para el Consejo Asesor Presidencial para la Reforma Previsional, Tema 5: Los Compromisos Fiscales”. (Estuvo disponible en www.consejoreformaprevisional.cl hasta el viernes 9 de junio de 2006, pero fue retirado después de esa fecha. Disponible con el autor.)

Polackova, Hana (1998): “Government Contingent Liabilities: A Hidden Risk to Fiscal Stability”. Policy Research Paper No 1989, The World Bank, Washington D.C.

Polackova, Hana (1999): "Contingent Government Liabilities: A Hidden Fiscal Risk". En Finance \& Development, Vol. 36 (March), pp. 46-49, Fondo Monetario Internacional, Washington, D.C.

Riesco, M. (2005): “Chile: Factibilidad de una Pensión Básica Universal”. Estudio preparado por CENDA para el Instituto de Normalización Previsional, en www.cep.cl

Roy, A. D. (1950): "The Distribution of Earnings and of Individual Output”. En The Economic Journal, Vol. 60, № 239, pp. 489-505.

Sinn, H. W. (2000): "Why a Funded Pension is Useful and Why is Not". En International Tax and Public Finance, 7, pp. 389-410.

Superintendencia de AFP (2002): "El Sistema Chileno de Pensiones”. Quinta edición. En www.safp.cl 
Valdés, S. (2002): Políticas y Mercados de Pensiones: Un Texto Universitario para América Latina. Ediciones Universidad Católica.

Valdés, S. (2005): "Pay as-you-go Securities: Securitization of Taxes Implicit in PAYG Pensions”. En Economic Policy, 42, abril, pp. 217-265.

Wagner, G. (1991): "La Seguridad Social y el Programa de Pensión Mínima Garantizada”. En Estudios de Economía, Vol. 18 No 1 (junio).

Zurita, Salvador (1994): "Minimum Pension Insurance in the Chilean Pension System”. En Revista de Análisis Económico, Vol. 9, № 1 (Junio), pp. 105-126. 